\title{
The effectiveness of non-native fish removal techniques in freshwater ecosystems: a
}

4 Trina Rytwinski ${ }^{1,2 *}$, Jessica J. Taylor ${ }^{1,2}$, Lisa A. Donaldson ${ }^{1,2}$, J. Robert Britton ${ }^{3}$, David R. Browne ${ }^{4}$, Robert E. Gresswell ${ }^{5}$, Mark Lintermans ${ }^{6}$, Kent A. Prior ${ }^{7}$, Marlow G. Pellatt ${ }^{8}$,

6 Chantal Vis ${ }^{9}$, Steven J. Cooke ${ }^{1,2}$

$8{ }^{1}$ Canadian Centre for Evidence-Based Conservation and Environmental Management, Institute of Environmental Sciences, Carleton University, Ottawa, ON, Canada; ${ }^{2}$ Fish

10 Ecology and Conservation Physiology Laboratory, Department of Biology, Carleton University, Ottawa, ON, Canada; ${ }^{3}$ Department of Life and Environmental Sciences,

12 Faculty of Science and Technology, Bournemouth University, Poole, UK; ${ }^{4}$ Canadian Wildlife Federation, Ottawa, ON, Canada; ${ }^{5}$ US Geological Survey, Northern Rocky

14 Mountain Science Center, Bozeman, MT, USA; ${ }^{6}$ Institute for Applied Ecology, University of Canberra, Canberra, ACT, Australia; ${ }^{7}$ Parks Canada, Ecosystem

16 Restoration, Gatineau, QC, Canada; ${ }^{8}$ Parks Canada, Natural Resource Conservation, Protected Areas Establishment and Conservation Directorate, Vancouver, BC, Canada; 9

18 Parks Canada, Marine Policy Division, Protected Areas Establishment and Conservation Directorate, Gatineau, QC, Canada

$20{ }^{*}$ Corresponding author: Email: trytwinski@hotmail.com; Phone (mobile): 613-614-8214 Word count: 12,893 (text only); 21,698 (inclusive) 


\section{Abstract}

In aquatic systems, biological invasions can result in adverse ecological effects.

24 Management techniques available for non-native fish removal programs (including eradication and population size control) vary widely, but include chemicals, harvest

26 regimes, physical removal, or biological control. For management agencies, deciding on what non-native fish removal program to use has been challenging because there is little

28 reliable information about the relative effectiveness of these measures in controlling or eradicating non-native fish. We conducted a systematic review, including a critical

30 appraisal of study validity, to assess the effectiveness of different non-native fish removal methods, and to identify the factors that influence the overall success rate of each type of

32 method. We found 95 relevant studies, generating 158 data sets. The evidence base was dominated by poorly documented studies with inadequate experimental designs $(76 \%$ of

34 removal projects). When the management goal was non-native fish eradication, chemical treatments were relatively successful (antimycin 75\%; rotenone $89 \%$ ) compared to other

36 interventions. Electrofishing and passive removal measure studies indicated successful eradication was possible (58\% each respectively) but required intensive effort and

38 multiple treatments over a number of years. Of these studies with sufficient information, electrofishing had the highest success for population size control (56\% of data sets).

40 Overall, inadequate data quality and completeness severely limited our ability to make strong conclusions about the relationships between non-native fish abundance and

42 different methods of eradication and population control, and the factors influencing the overall success rate of each method. Our review highlights that there is considerable

44 scope for improving our evaluations of non-native fish removal methods. It is 
recommended that programs should have explicitly stated objectives, better data

46 reporting, and study designs that (when possible and appropriate) incorporate replicated and controlled investigations with rigorous, long-term quantitative monitoring. Future

48 research on the effectiveness of non-native fish removal methods should focus on: (1) the efficacy of existing or potentially new removal measures in larger, more complex

50 environments; (2) a broader range of removal measures in general, and (3) phenotypic characteristics of individual fish within a population that fail to be eradicated or

52 controlled.

54 Keywords: alien invasive species, restoration, nonindigenous species, invasive species, invasion biology, evidence-based policy.

56 


\section{Introduction}

68 In aquatic systems, biological invasions can result in adverse ecological effects (Gozlan et al. 2009; Ricciardi and MacIsaac 2011). Invasive species threaten biodiversity

70 (Vitousek et al. 1997; Sala et al. 2000; Koel et al. 2005) and impose considerable economic costs (Pimentel et al. 2005), placing increased demands on policy-makers,

72 resource managers, and scientists (Simberloff et al. 2013). The introduction and spread of aquatic invasive species can occur by natural or human pathways, including: shipping

74 networks and canals (Ruiz et al. 1997; Levine and D'Antonio 2003), escapes from aquaculture, aquaria and ornamental trade (Padilla and Williams 2004), stocking (Gozlan

76 et al. 2010), bait bucket transfers (Ludwig and Leitch 1996), and recreational boating (Clarke Murray et al. 2011). Additionally, the secondary spread of introduced species

78 poses considerable challenges for resource managers (Fredenberg 2002; Lintermans 2004; Vander Zanden and Olden 2008).

80 Options for managing non-native fish species can include no action, control and/or containment, population extirpation, and/or species eradication (Varley and Schullery

82 1995). Containment, such as implementing barriers, is used to prevent the spread of nonnative species into novel environments (Fausch et al. 2006; Finnoff et al. 2007; Peterson

84 et al. 2008; Britton et al. 2011a). However, where containment is not possible or has not been successful, eradication has been proposed as a valid option for managing biological

86 invasions (Rinne and Turner 1991; Genovesi 2005). Eradication is the elimination of whole fish populations or fish species from distinct habitats or bodies of water (Gresswell 88 1991), and is usually aimed at new introductions that are confined to localized spatial areas (Britton et al. 2011b). Eradication approaches tend to be targeted, for example, by 
90 exploiting vulnerable periods in the life cycle (Buhle et al. 2005; Syslo et al. 2013) or by focusing on areas of high abundance (Meronek et al. 1996). When complete eradication is

92 infeasible or unsuccessful, control methods can be implemented to suppress the nonnative population either through selective removal or eradication of determinate

94 populations from lentic habitats where there is high risk of natural dispersal into lotic habitats (Britton and Brazier 2006).

The types of fish management techniques available to resource managers to implement fish eradication and population control programs for non-native species can

98 vary widely. Methods include chemical treatments, harvest regimes, physical removal, or biological control (Meronek et al. 1996). The effectiveness of chemical treatments (e.g.,

100 rotenone, antimycin) depends on environmental conditions (e.g., water temperature, depth, $\mathrm{pH}$, discharge, target fish species, hydrology, substrate composition, and areas of

102 groundwater recharge; Finlayson et al. 2000); there are also concerns of unintended consequences when non-target species are affected by chemical treatments (Vinson et al.

104 2010). Harvest regimes can include intentional over-fishing (e.g., gill netting and angling) of target species (Paul et al. 2003; Syslo et al. 2011; Gaeta et al. 2015) or modification of

106 angling regulations (e.g., favour overharvest of target species). Physical removal techniques can include traps, electrofishing, and/or netting programs, and biological

108 controls can include the introduction of predators, intraspecific manipulation, or targeted pathological reactions (Davis and Britton 2015). When implementing fish management 110 programs, risk analysis assists selection of the commensurate strategy and its likelihood of success (Britton et al. 2011a). The risk analysis includes identification and assessments 
112 of hazards, including predicting the likelihood and severity of adverse effects (Koel et al. 2010; Copp et al. 2016).

114 The success of non-native fish management approaches can vary greatly depending on objectives, such as whether control, eradication, or containment (amongst others) was

116 the ultimate goal of the project. As can be expected given the complexities of the natural environment, success can be difficult to quantify and some approaches can be

118 unsuccessful despite best efforts (Simberloff et al. 2013; Rinne and Turner 1991; Meronek et al. 1996). Failure of non-native fish management techniques can occur

120 because of a number of factors, including ineffective capture techniques (e.g., sizespecific efficiencies), habitat complexity (e.g., areas of refuge and plant density) and

122 water-body size, species-specific factors (e.g., size and habitat preferences), and physical water properties (e.g., water chemistry, temperature, and water depth; Britton et al.

$1242011 b$ ). Determining the outcomes of management interventions, especially when restoration of freshwater ecosystems is a goal (e.g., to eradicate non-native target fish

126 species from a specific waterbody or return the waterbody to its pre-invasion state), requires long-term evaluation and assessment in relation to meeting the objectives (Rinne

128 and Turner 1991; Meronek et al. 1996; Britton and Brazier 2006). Post-program evaluation and assessment is required not only to determine the effectiveness of

130 techniques but also to explore the cost-effectiveness and cost/benefit of each strategy.

There have been a number of traditional reviews conducted on the efficacy of fish 132 management measures (e.g., Corfield et al. 2007; Ayres and Clunie 2010; Halfyard 2010; Kolar et al. 2010; Britton et al. 2011b). Some reviews have primarily focused on removal 134 of 'undesirable' (and not necessarily non-native) fish species (e.g., Schuytema 1977; 
Meronek et al. 1996; Wydoski and Wiley 1999), a particular type of management

136 intervention (e.g., chemicals: Lennon 1970; Rinne and Turner 1991; Rowe 2001; Rayner and Creese 2006; Clearwater et al. 2008), or on interventions for a particular management

138 objective i.e., prevention or containment of non-native fish (e.g., Elkins et al. 2009; Sorensen 2015). While these reviews are valuable and may be reliable, they are also

140 susceptible to a range of biases that can reduce their reliability (Petticrew and Roberts 2008). Here, we use a 'systematic review' approach (Pullin and Stewart 2006) to evaluate

142 the existing literature base to assess the effectiveness of different non-native fish eradication and population control methods. For the purpose of this review we

144 collectively refer to these methods as "removal measures". What sets apart systematic reviews from most traditional reviews in the field of applied ecology is that systematic

146 reviews provide a rigorous, objective, and transparent methodology to assess the impacts of human activity and effectiveness of policy and management interventions (Roberts et

148 al. 2006; O’Leary et al. 2016; Cooke et al. 2017; CEE 2018).

Specifically, the objective of the systematic review was to evaluate the existing

150 literature base to assess the effectiveness of different non-native fish removal methods, and to identify the factors that influence the overall success rate of each type of method,

152 in order to better inform management agencies who routinely have to decide when, where and how non-native fish eradication programs should be implemented. The review also

154 aimed to identify knowledge gaps and suggest areas for new research. 


\section{Approach}

\section{Search strategy and study selection}

The search strategy for this review was structured according to the collaboration for

158 environmental evidence's guidelines (CEE 2013) and followed that published in the protocol (Donaldson and Cooke 2016), with changes stated in Text S1. The search

160 strategy was developed to include a variety of article types, including primary literature in peer-reviewed journals and grey literature (e.g., theses, government papers,

162 organisation reports, and consultant reports, etc.) and used 5 online publication databases [(1) Waves (now the Federal Science Library), (2) ProQuest Dissertations \& Theses

164 Global, (3) Science.gov, (4) ISI Web of Science Core Collection, and (5) Scopus; Nov 2016], and the search engine Google scholar (first 500 hits; Dec 2016). Whenever

166 possible, the following search string was applied throughout the searches (in Web of Science format): [(Fish*) AND (Invasive\$ OR "Non Native\$" OR NonNative\$ OR

168 Alien\$ OR Exotic\$ OR introduced OR "non indigenous" OR Nonindigenous OR IAS OR "Invasive species" OR "Alien invasive\$") AND ("Fresh water" OR Freshwater OR

170 Stream\$ OR Water\$ OR River\$ OR Lake\$ OR Reservoir\$ OR Pond\$) AND (Hydraulic OR Screen* OR Weir\$ OR Net OR Nets OR Netting OR Gill OR Trammel OR Hoop OR

172 Trap OR Cast OR Lift OR Sein* OR Trawl* OR Electrofish* OR Electric OR Cull OR Piscicide\$ OR Rotenone OR Antimycin OR Fintrol OR Explosive\$ OR Primacord OR

174 Biocide OR Angl* OR Trotline\$ OR "Rod and reel" OR "Limb lin*" OR Limblin* OR "De water*" OR Dewater* OR "Drawn down" OR Drawndown OR Pump*) AND

176 (Restor* OR Rehabilitat* OR Remov* OR Eradicat* OR Control* OR Suppress* OR Reduc* OR Renovat* OR Exclusion OR Exclud*)]. Full details of the search strings used 
178 and the number of articles found from each source are provided in Text S2. English search terms were used to conduct all searches in all databases and search engines. No

180 date, language, or document type restrictions were applied during the searches.

We also searched for relevant information on 28 specialist organization websites

182 (see Text S3 for list of websites) in February 2017 using the abbreviated search terms [i.e., search strings (1) fish AND eradication; (2) invasive AND eradication; (3)

184 introduced AND eradication]. Page data from the first 20 search results for each search string were extracted (i.e., 60 hits per website), screened for relevance, and searched for

186 links or references to relevant publications, data and grey literature. Potentially useful documents that had not already been found using publication databases or search engines 188 were recorded.

In addition, reference sections of accepted articles and 60 relevant reviews (see

190 Table S1 for a list of reviews) were hand searched to evaluate relevant articles that were not found using the search strategy. Stakeholders and advisory team members were

192 consulted for insight and advice for new sources of information (i.e., Parks Canada, Canadian Wildlife Federation, United States Geological Survey, and British and

194 Australian academics). We also issued a call for evidence to target sources of grey literature through presentations at meetings and conferences (e.g., Ontario Biodiversity

196 Summit, Fisheries and Oceans Canada headquarters, American Fisheries Society Ontario Chapter Annual Meetings), relevant list serves (e.g., Canadian Conference for

198 Fisheries Research, American Fisheries Society), and social media (e.g., Twitter, Facebook) and email, to alert the community of this systematic review and to reach out to 
200 area experts for further recommendations and for provision of relevant unpublished material (summer of 2016 \& February 2017).

\section{Article screening and study inclusion criteria}

Articles found by searches in databases and search engines were screened in two distinct

204 stages: (1) title and abstract, and (2) full text. Articles or datasets found by other means than database or search engine searches (i.e., specialist website or other literature

206 searches) were entered at the second stage of this screening process (i.e., full text). Prior to screening the full set of results at each stage, consistency checks of reviewers were 208 undertaken on a subset of articles and discrepancies discussed (see Text S4A for further details). A list of all articles excluded on the basis of full-text assessment is provided in

210 Table S2, together with the reasons for exclusion.

Each study had to pass each of the following criteria in order to be included:

\section{1. Relevant subjects}

The relevant subjects of this review were non-native freshwater fish. We did not consider

214 articles that implemented a management technique with the goal of eradicating all fish species, including native species, or when targets were only identified as 'undesirable',

216 'trash', or 'pan' fish species. The focus on non-native freshwater fish for this systematic review primarily stemmed from its identification as a priority for the Parks Canada

218 Agency (stakeholders), a federal government agency in Canada mandated with protecting the natural and cultural heritage of sites (i.e., national parks and reserves, national marine

220 conservation areas and national historic sites). The maintenance and restoration of ecological integrity represent core principles of Parks Canada such that they employ

222 biologists and restoration specialists tasked with engaging in activities such as fish 
eradication and population control of non-native species. We acknowledge that articles

224 reporting information on removal measure efficacy for non-native fish species may also contain relevant information in certain contexts; however, they do not directly address

226 our main research question. We also only considered wild or stocked systems, excluding articles related to management in aquaculture, hatcheries, and nurseries. Note, we

228 excluded articles on sea lamprey (Petromyzon marinus) from the review for a number of reasons: (1) there are extensive multi-national control programs ongoing (e.g., the

230 Laurentian Great Lakes) that are not rivaled for any other freshwater fish species (reviewed in Siefkes 2017); (2) the amount of money that has been applied to their

232 control is not comparable to other species thus far, and (3) their taxonomy (as agnathans - one of the few freshwater jawless fishes) and ecology (i.e., parasitic life style) is such

234 that it makes it difficult to compare to other fish species. In this regard, our search terms were not developed to capture literature on lamprey specifically.

\section{2. Relevant types of interventions}

The intervention refers to a fish eradication or population control method. Measures

238 could include (but not limited to) one or more of: (1) chemical treatment; (2) harvest regimes (i.e., intentional over-fishing of target species, or modification of angling

240 regulations); (3) physical removal; (4) biological control [e.g., introduction of predators, intraspecific manipulation (i.e., adding competitor species), sterilization (i.e., chemical or

242 genetic manipulation), or targeted pathological reactions]; (5) environmental (e.g., lowering water level); (6) other (e.g., explosives), or (7) any combination of the above

244 methods. This review focused only on measures aimed at eradication or population control of non-native fish. We excluded articles that implemented measures to prevent the 
246 introduction of a non-native fish species or to contain the spread of non-natives (e.g., barrier screens, behavioural avoidance measures i.e., use of food/competitor/predatory

248 odors or chemosensory cues, lights). Furthermore, we excluded articles that only presented preliminary test findings of a larger project or a stepping-stone project that was

250 used to determine whether a management technique or product could be used as a removal measure in the field. For example, Schill et al. (2016) suggested a potential

252 alternative to manual or piscicide fish removal in the use of the Trojan Y Chromosome (TYC) program in which hatchery-produced genetically YY male fish would be regularly

254 released into an undesired population over time, skewing the population towards $100 \%$ males, theoretically resulting in wild population extirpation. However, this was just a

256 preliminary study in the development of TYC technology and did not evaluate the method as an eradication technique. These types of excluded articles could also include,

258 for example, laboratory studies determining the toxicity level requirements (i.e., exposure concentrations to chemicals) and/or environmental variables that may affect eradication

260 technique performance (e.g., Marking et al. 1983).

\section{Relevant types of comparators/study designs}

262 This review compared outcomes based on articles that used Before-After (BA), ControlImpact (CI), or a combination of these comparisons Before-After-Control-Impact (BACI)

264 and randomized controlled trial (RCT) study designs. Relevant comparators included: (1) similar sections of the same waterbody with no intervention (i.e., upstream condition); (2)

266 separate but similar waterbodies with no intervention (i.e., waterbodies with non-native fish present but have not had any fish management projects conducted in them); (3)

268 before intervention data within the same waterbody, or (4) an alternative intervention 
type conducted on the same or different waterbodies. Theoretical studies (e.g., individual-

270 based models or population viability analysis), review papers and policy discussions were excluded.

\section{4. Relevant types of outcomes}

The outcome of interest consisted of qualitative and quantitative information on the

274 measured effect of treatment. Measured effect of treatment generally needed to indicate some change in abundance of the target species relative to before treatment or control.

276 We used a broad definition of abundance to include population size (or relative size), population density (or relative density), number of fish removed (with no estimate of

278 population size/density), removal efficiency, catch per unit effort (CPUE), biomass (e.g., total weight of fish removed), and species presence or absence from an area or

280 management unit (as an index of high vs. low abundance for population control, or the success/failure of an eradication attempt).

282 Additionally, only full text articles written in English or French were included.

\section{Critical Appraisal}

284 All articles that had passed full-text screening were critically appraised to assess whether the evidence was valid for answering our review question. This critical appraisal process

286 was used to assess the absolute and relative importance of different sources of bias and data validity elements (e.g., temporal and spatial replication). Here and throughout this

288 review, we refer this assessment of susceptibility to bias, as study validity. This critical appraisal was based on the entire evidence found on an individual removal study, not on

290 individual articles. In these situations, we cite the article (i.e., primary study source) with the most comprehensive information (or in some cases, the most recent publication) and 
292 identify supportive articles as supplementary articles (see Table S3 for a list of supplementary articles and Text S4B for further details of critical appraisal). If a study

294 contained more than one project (i.e. differed with respect to one or more components of critical appraisal; see Table 1), each project received an individual validity rating and was

296 labelled in the data extraction table with letters (e.g., Ertel et al. 2017 “A/B/C/D”). Critical appraisal was conducted using a predefined framework developed to: (1) assess

298 the risk of bias across a range of variables for each study (see Table 1), and (2) assign each project with a critical appraisal category based on these variables. The framework

300 was based on an evaluation of the following criteria: study design (BACI, BA, CI), temporal and spatial replication (see Text S4C for definitions of pre-, during- and post-

302 removal periods), measured outcome (quantitative, quantitative approximation, semiquantitative, or qualitative), intervention application coverage (appropriateness of

304 intervention based on species/system), control matching (how well matched the intervention and comparator sites were in terms of habitat type), and confounding factors

306 (environmental or other factors that differ between intervention and comparator sites). Each criterion was scored at a 'high', 'medium', 'low', or 'very low' level based on the

308 framework outlined in Table 1. The project was given an overall 'very low' validity if it scored very low for replication. The study was given an overall 'low' validity if it scored

310 low for one or more of the criteria. If the project did not score low for any of the criteria, it was assigned an overall 'medium' validity. If the study scored only high for all of the

312 criteria, it was assigned an overall 'high' validity (see Table S4 for assessment for the individual studies). 


\section{Data extraction strategy}

Data on potential effect modifiers and other metadata were extracted from the included

316 primary study source or their supplementary articles whenever available. Data extracted included: study location (e.g., country, longitude, latitude, waterbody name), and species

318 information, the applied intervention(s) and its frequency, the outcomes, the methodology and other potentially confounding factors that were identified as possible reasons for

320 heterogeneity (i.e., waterbody type, area, depth, open or closed waterbody system, time since invasion, seasonality of intervention application(s), presence of containment

322 measures prior to or during study (e.g., barrier screens), study design, duration of outcome sampling). We also gathered general study summary information, i.e., brief

324 statement of study objective, categorized goal of the applied intervention(s) as stated by authors, and summarized results (Table S5). See Text S4A for details of data extraction

326 consistency checks.

The data extraction form was piloted on a representative sample of studies, to

328 represent the range of available studies. At this stage, it became apparent that there was a lack of studies reporting useful quantitative data for both the intervention group and the

330 comparator group. For example, it was common for studies to only have qualitative information for the outcome measure prior to intervention (i.e., presence of a non-native

332 fish species) and then have a quantitative value after intervention (i.e., number of fish killed). This precluded our ability to conduct formal synthesis of quantitative outcomes

334 across studies, i.e. meta-analysis. Therefore, regarding the assessment of intervention effectiveness, each study (or data set within a study) was given an effectiveness rating by

336 the reviewer (Table 2). These ratings were based on: (1) a comparison of quantitative data 
from the comparator group and the intervention group (when possible); or (2) author's

338 conclusions on the success/failure of the intervention(s) for the stated goal (Table 2). If neither quantitative data, nor the author's conclusions on the success of the

340 intervention(s) were provided, the effectiveness rating was classed as undetermined. This effectiveness rating was the basis for the intervention effectiveness variable used for

342 narrative synthesis.

\section{$344 \quad$ Findings}

\section{Review descriptive statistics}

\section{Literature searches and screening}

Fig. 1 shows the step-by-step results from the search and screening process. Our literature

348 search from the five scientific databases and Google Scholar yielded 2,561 unique records after duplicate removal. After full-text screening, 56 relevant articles met our

350 inclusion criteria from the publication databases and search engine. Another 60 relevant articles were included after full-text screening from specialist websites, bibliographies of

352 relevant reviews, and other searches. A further 24 articles were found from searching included article bibliographies, resulting in 140 articles that underwent data extraction

354 and study validity assessment (Fig. 1). After exclusions and combining overlapping articles, 95 'studies' were included in the review synthesis (see Table A1 and Table S3

356 for a list of the included primary study sources). These 95 studies generated 158 data sets (i.e., studies could have $>1$ datasets if they targeted more than 1 non-native species, 358 and/or evaluated different removal measures in different waterbodies). 
The following descriptions are based on the primary (or only) source of the study

362 information (i.e., the most comprehensive source, in cases where supplementary articles were identified).

364 Fifty-six of the primary articles reported on research that was directly or indirectly related to removal of at least one non-native freshwater fish species and were published

366 in peer-reviewed journals. Twenty-five are better described as monitoring or project reports from government or consultant groups. The remaining 14 articles were in the

368 form of conference proceedings (6), theses (3), newsletters (2), a book chapter (1), a website (1), and a conference presentation (1).

$370 \quad$ Primary articles were published from 1939 to 2017 . Only 10 of the 95 articles were published before 1990. Years of publications were distributed fairly evenly over the

372 period of 1980-2004, after which an increase in the number of articles can be seen over the more recent years (2005-2017) (see Fig. 2).

\section{Study validity assessment}

376 Validity assessments were conducted for individual removal projects, of which there were 106 identified from the 95 studies (see Table S4). For the majority of the projects,

378 we found the validity of the available evidence to have very low (22 of 106 projects) or low (58 projects) study validity (very high or high susceptibility to bias). Only 1 project

380 was classified as having high study validity (Closs et al. 2001). In the remaining 25 projects, we classified the susceptibility to bias as medium (see Table 3 ). Projects were

382 assessed as having very low study validity when there was only 1 before or after year assessment period and that period was $>5$ years either prior to or following intervention, 
384 or there was insufficient information on the before or after assessment period i.e., no preintervention dates were provided. The majority of projects classified as having low study

386 validity had at least one qualitative outcome measure, lacked sufficient information on the application coverage of the intervention, and/or had low spatial/temporal replication

388 (i.e., $1 \mathrm{BA}$ or CI replicate) (Table 3). Projects of medium susceptibility to bias were assessed as such primarily because they used a BA, CI, or incomplete BACI design [i.e.,

390 data is missing for certain components of the design (e.g., missing before data for control sites), preventing the data from quantitative analysis using the full BACI design], had

392 moderate spatial/temporal replication, and/or used quantitative approximations for both intervention group and comparator outcome measures (Table 3).

394 Based on our study validity assessments, the quality of the available evidence seems to have improved during the late 1980's; however, the proportion of the lower 396 quality studies in a given time period has stayed relatively similar since then (Fig. 3).

$398 \quad$ Narrative synthesis

\section{Study descriptions}

400 Project goal. - Nearly half of the data sets included in this review had a goal of nonnative fish eradication ( 77 of 158 data sets). Control of non-native fish population size

402 (i.e., a reduction in abundance, density, and biomass) was the goal of 69 of the data sets (44\%). For 12 data sets ( $8 \%$ ) either eradication or population control was stated as the

404 goal of the project, or it was unclear whether complete eradication was the actual goal since partial removal was considered to be a beneficial outcome. In 55 of the data sets, a

406 change in species composition (i.e., a shift from non-native to native fish species, or an 
increase in native species abundance) was also identified as a goal of the project.

408 Furthermore, in 2 data sets, a change in target species size was stated as a goal in addition to the suppression of non-native fish population size. For the purposes of this review, we

410 only focus our synthesis on information related to non-native fish eradication or population control i.e., we do not summarize information on population structure (e.g.,

412 length, age, weight) or composition.

414 Geographical location. - Most of the studies in this review were performed in North America ( $62 \%$ of data sets) - more than $80 \%$ of which were in the United States of 416 America (USA) -, with some carried out in Oceania (26\%), Europe (11\%), and Africa (1\%) (Fig. 4). When considering all studies across North America, there was nearly a

$41850 / 50$ split between eradication and control goal-oriented projects. However, when isolating Canadian from American projects, we found that the goal of most projects in

420 Canada was non-native fish eradication ( $73 \%$ of datasets), whereas, the focus was slightly more on population control in the USA (54\% of datasets) (Fig. 4). Within Europe, the

422 most frequently reported project goal was population control ( $58 \%$ of datasets); whereas, eradication was most commonly stated as the goal of projects in Oceania (69\% of 424 datasets).

Population. - Studies targeted 42 non-native fish species from 30 genera for removal.

426 The most common targeted non-native fish were brook trout (Salvelinus fontinalis; 19 studies, 29 data sets), rainbow trout (Oncorhynchus mykiss; 13 studies, 22 data sets),

428 common or koi carp (Cyprinus carpio; 13 studies, 18 data sets), smallmouth bass (Micropterus dolomieu; 7 studies, 8 data sets), northern pike (Esox lucius; 6 studies, 9 
430 data sets), brown trout (Salmo trutta; 6 studies, 7 data sets), and European perch (Perca fluviatilis; 6 studies, 6 data sets). Less than 19\% of studies targeted more than 1 non-

432 native fish species for removal. The majority of studies implementing a removal measure were conducted within lakes/ponds (43\% of studies), and rivers/streams/creeks ( $42 \%)$, 434 with a few in reservoirs $(11 \%)$, wetlands $(3 \%)$, and canals $(1 \%)$.

In the USA, studies targeted 24 non-native fish species from 17 genera, the most 436 common being rainbow and brook trout, and common carp (Table S6). Seven non-native fish species were targeted for removal in Canada; the most frequently targeted were 438 brook trout (Table S6). Eight non-native fish species were targeted for removal in Europe, the most common being the topmouth gudgeon (Pseudorasbora parva) (Table

440 S7). In Australia and New Zealand, 9 and 5 non-native fish species were targeted respectively, with the majority of species including common carp, European perch, and 442 goldfish (Carrasius auratus) (Table S7).

444 Intervention. - The vast majority of studies implemented one main intervention to either eradicate or control population size of a non-native fish species (70\% of data sets; Fig. 5).

446 Of the studies that used one main intervention, the most commonly used removal techniques included measures categorized as either physical (53\% of data sets) or 448 chemical (38\%). Studies that only used harvest, environmental, or biological type measures were used less frequently $(6 \%, 2 \%$ and $1 \%$, respectively). Physical and 450 chemical measures were most frequently combined with another measure (55\% and 20\% of data sets, respectively) either simultaneously or consecutively than other removal 452 measure categories. 
Of the studies that implemented physical removal measures (either alone or in 454 combination with another measure), the majority used electrofishing by boat or backpack, or passive removal measures including hoop-, gill-, or fyke-nets, or traps (Table 4).

456 The majority of studies used chemical treatments for removal using rotenone, followed by antimycin (trade name, Fintrol ${ }^{\circledR}$ ) (Table 4). Only two types of harvest measures were 458 used and with the same frequency (i.e., angling and a combination of passive and active netting; Table 4). For biological control measures, predator introduction was the only

460 measure utilized. Six studies used an environmental measure in the form of lake dewatering, either alone ( 2 data sets) or in combination with another measure ( 5 data

462 sets). Only one study used an alternative form of removal through the use of explosives, and only in combination with other measures (Table 4).

464 Just over $46 \%$ of data sets that implemented a removal measure, also included containment measures (i.e., pre-existing measures before start of study, implemented 466 during study period, or natural barriers) to prevent/reduce the spread of non-native(s). For studies that reported accurate information on the time since invasion (i.e., date of

468 discovery of a non-native in the study waterbody to the start of the removal program; $59 \%$ of data sets), $12 \%$ initiated removal attempts within the first year of discovery.

Study design and comparator. - The availability of outcome data from different

472 assessment periods of each of the included removal studies is shown in Fig. S1-S3, along with study validity assessments. Of the 158 data sets, 136 used - in a broad sense - a BA

474 design. In 73 of these data sets, studies reported data collected before and during the intervention, but not afterwards (BD designs); in nearly $44 \%$ of these BD data sets, the 
476 actual before date period was either not stated or data were collected more than 5 years prior to the start of the intervention (deficient BA comparison). In 63 other BA data sets, 478 outcome data were reported before, during and after intervention (BDA designs); $14 \%$ of these BDA had a deficient BA comparison. Another 17 of 158 data sets used a BACI 480 design; 12 of which did not report outcome data after the intervention (BDCI design) and 5 which did report after data (BDACI design). The remaining 5 data sets ( 3 articles) in 482 the review employed a CI design (Control-Impact).

For designs that incorporated control sites (i.e., CI and BACI designs), most data 484 sets used control sites in the form of the up- or down-stream condition within the same waterbody as the impact site(s) with the applied intervention (77\% of CI and BACI data 486 sets). For the remaining CI and BACI data sets, control sites were different waterbodies with no intervention (i.e., waterbodies with non-native fish present but had not had any 488 fish management projects conducted in them).

For study designs that reported before intervention data, the majority collected 490 outcome data $\leq 1$ year prior to implementing a removal measure $(81 \%$ of BA and BACI design data sets). The available outcome data for the before period ranged from 1 to 11 492 years (Fig. S1-S3). For designs that collected 'true' after intervention outcome data, 49\% of data sets only did so $\leq 1$ year after the intervention was applied. The available outcome

494 data for the 'true' after period ranged from 1 to 19 years (Fig. S1-S3). In all cases of the CI designs, comparisons were made during the intervention periods i.e., there were no 496 'true' after monitoring periods. 
The number of control sites used in $\mathrm{CI}$ and $\mathrm{BACI}$ designs ranged from 1 to $4 ; 55 \%$

498 of data sets only used 1 control site. Although the number of impact sites used in these studies had a greater range (1-13) most (55\% of data sets) only used 1 impact site.

500

Outcomes. - The outcomes that we extracted from studies were dominated by semi-

502 quantitative observations ( $53 \%$ of data sets), whereby the outcome measure for the comparator group was the presence of a non-native fish (a qualitative measure), and the

504 outcome measure of the intervention group was some form of a quantitative abundance measure [e.g., the number of fish killed, abundance (or density), catch per unit effort

506 (CPUE), biomass]. For studies that collected quantitative outcome measures (39\% of data sets), nearly $43 \%$ of these reported more than one outcome measure indicating some

508 change in 'abundance' of target species with the intervention group relative to the comparator group. The three most commonly reported outcome measures were: (1) the

510 number of fish killed (88 cases); (2) an estimate of population size (48 cases); and (3) CPUE (32 cases). Relatively few studies reported outcomes in the form of abundance (or

512 density) (11 cases), percent removal efficiency (10 cases), or biomass (e.g., total weight of fish removed/recovered) (5 cases). Qualitative observations were made in 9\% of data 514 sets.

516 Evidence of effectiveness

Chemical treatment for eradication

518 Nearly $26 \%$ of all data sets used a fish toxicant alone for eradication attempts on nonnative fish (i.e., no other main interventions were used). The two toxicants used were 
520 antimycin $\mathrm{A}\left(\right.$ Fintrol $\left.^{\circledR}\right)$ (6 articles, 9 data sets) and rotenone (23 articles, 32 data sets), both of which are considered general-use piscicides (i.e., toxic to all fish). Study

522 validities for effective antimycin data sets of eradication were distributed fairly evenly over the very low, low, and medium assessments; whereas, the frequency of low validity

524 studies was higher than either the very low or medium assessments for effective rotenone data sets (Fig. $6 a$ and $b$ ).

Antimycin. - Antimycin was reported effective in eradicating a non-native fish in $75 \%$ of

528 data sets (Fig. 6a). Geographically, studies implementing antimycin alone were located in a few US Rocky Mountain and Southwest states, and a single study in eastern Canada

530 conducted in the mid 1970s. Two studies applied the toxicant in lakes (Hooper and Gilbert 1978; Baker et al. 2010); whereas, all others were implemented in perennial

532 creeks. Only a single study with 2 data sets used a BACI study design for evaluations of antimycin (Marks et al. 2010); all others employed a BA study design. The number of

534 applications of antimycin varied from 1 to 3 , with $78 \%$ of the antimycin data sets applying more than 1 application, and over varying times of the year. The number of

536 'true' post-monitoring years (not including the last during intervention year) ranged from 0 to 3 years after the last (or only) application of antimycin, most were $\leq 1$ year after 538 treatment (56\% of antimycin data sets). One study (Meffe 1983) was unsuccessful in eradicating a non-native fish from a shallow spring after a single antimycin treatment.

540 See Table S8 for summary characteristics and results of studies implementing antimycin alone for eradication of a non-native fish species. 
Rotenone. - Rotenone was reported effective in eradicating a non-native fish in $89 \%$ of

544 data sets (Fig. 6b). Rotenone was more widely and commonly used internationally than antimycin. The majority of rotenone treatments occurred in lakes ( $41 \%$ of rotenone data

546 sets), followed by ponds $(25 \%)$, creeks $(19 \%)$, rivers $(6 \%)$, reservoirs $(6 \%)$, and lagoons (3\%). When looking at national trends, the number of successful eradications was greater

548 than unsuccessful eradication attempts in all countries except Canada, where there was an equal number of each. For the countries that most commonly used rotenone, the

550 percentage of effective eradication attempts with rotenone use was greater for USA than for Australia ( $87 \%$ vs. $44 \%$, respectively). In one study, the eradication attempt was rated

552 as partly effective since the rotenone did result in eradication in all 7 streams treated; however, the non-native later re-established in one creek and the lower reaches of

554 another, as a result of a suspected deliberate re-introduction by anglers (Lintermans and Raadik 2003). Additionally, the eradication effectiveness was classified undetermined for 556 one data set in another study (i.e., Carrasius auratus, Hall 1988), where two non-native fish species were targeted for complete eradication but post-treatment results were only 558 presented for one of the two species.

There did not appear to be any patterns between rotenone effectiveness and the 560 number or seasonality of application(s), species, or water-body type. Furthermore, there were no discernible patterns between rotenone effectiveness and the presence of

562 containment measures (e.g., barrier screens), either implemented prior to or during the study, or those that occurred naturally (e.g., waterfall), or outcome category. All studies

564 using rotenone employed a BA study design. Rotenone was applied most often only once to a waterbody ( $75 \%$ of data sets), but up to two times; however, for two studies, 
566 insufficient details were provided on the number of applications (Swanson 1971;

Beamesderfer 2000). Although rotenone treatment was carried out at all times of the year,

568 fall was the most common season for application for studies both in the northern and southern hemisphere ( $49 \%$ of reported applications). The number of 'true' post-treatment

570 sampling years ranged from 0 to 19 years after the last (or only) application of rotenone, but the majority were conducted for $\leq 1$ year after treatment ( $59 \%$ of data sets).

572 Information on area or length of the waterbody treated was often not reported in these studies, limiting the assessment of the impact of this variable on rotenone effectiveness.

574 See Table S9 for summary characteristics and results of studies implementing rotenone alone for eradication of a non-native fish species.

Chemical treatment for population size control. - Only three data sets from 2 studies

578 implemented a chemical intervention alone to evaluate the efficacy of population size control of a target non-native fish (Fig. $6 c$ and $d$ ). One study targeting Eurasian ruffe

580 (Gymnocephalus cernuus) treated two rivers in Minnesota, USA, with TFM (3triflouromethyl-4-nitrophenol), a taxon-specific chemical used for control of sea lamprey

582 (Boogaard et al. 1996). Comparison of pre-treatment and post-treatment CPUEs indicated that the ruffe population was reduced by 97\% (Brule River) and 54\% (Amnicon River)

584 with the use of a single application of TFM. In both instances, post-treatment monitoring was short term (i.e., Brule River: $\sim 2$ weeks and again 2 months after treatment; Amnicon

586 River: 5 days after treatment) and study validities were classified as low because of small temporal repetition. In another study, Beamesderfer (2000) presented case studies, one of 588 which was not previously published that described - in very little detail - the chemical 
treatment of the Tenmile Lakes system in Oregon in 1968 with rotenone for bluegill

590 (Lepomis macrochirus). Although it was reported that treatment had initially been effective, 19 years of post-treatment monitoring showed bluegill quickly repopulated

592 (Beamesderfer 2000). Despite the long-term post-treatment monitoring, study validity was classified very low because of the limited information reported in the study.

\section{Physical removal for eradication}

596 Of the included data sets, $15 \%$ implemented a single physical removal measure, not in combination with any other main interventions, for eradication of a non-native fish. Two 598 general categories of physical removal measures, electrofishing (7 studies, 12 data sets), and passive netting or trapping (6 studies, 12 data sets), were used. In general, the

600 distribution of study validities across effectiveness ratings were similar between eradication attempts using electrofishing and passive netting/trapping measures (Fig. $6 e$

602 and $f$ ). The majority of studies, whether reporting effective and ineffective eradications, were assessed as having low study validities.

Electrofishing. - Electrofishing was reported effective in eradicating a non-native fish in

$60658 \%$ of data sets (Fig. 6e). All studies applying electrofishing alone in an attempt to eradicate a non-native fish species did so using backpack electrofishers. There were no 608 geographical differences in reported effectiveness between regions; most of these studies were conducted in the USA ( $83 \%$ of data sets).

610 Successful eradications used a greater number of treatments to a waterbody (mean: $10.9 \pm 2.57 \mathrm{SD})$ than unsuccessful eradication attempts $(4.0 \pm 2.34)(\mathrm{t}$-test: $t=2.15, d f$ 
$612=10, p=0.057)$. It should be noted that information on the number of times a waterbody was treated with electrofishing was not always clearly reported, but the approximate total

614 number of times a waterbody was treated over the course of the intervention period (or treated until the non-native fish species was no longer captured) varied widely from 3 to

616 24. Effective eradications were monitored from 1 to 3 years after the last treatment or until fish were no longer captured. Unsuccessful eradication attempts were those that: (1)

618 were investigating the effectiveness of electrofishing for either eradication or suppression of non-natives, or (2) it was unclear whether complete eradication was the actual goal

620 since partial removal was considered to be a beneficial outcome.

There were no apparent patterns between electrofishing effectiveness and the 622 number of during treatment years, the presence of a containment measure(s), or outcome category. Furthermore, all electrofishing evaluations were conducted in small lotic

624 systems; only a single study occurred on a relatively larger river (Pacas and Taylor 2015). In all cases, non-native targets were trout species, the majority of which were brook trout 626 (75\% of data sets). Four data sets from two studies used a BACI study design for evaluations of electrofishing (Thompson and Rahel 1996; Kulp and Moore 2000); all 628 others employed a BA study design. In all studies, electrofishing was applied for more than 1 year (range: 2-8 years). Table S10 for summary characteristics and results of 630 studies implementing electrofishing alone for eradication of a non-native fish species.

632 Passive netting/trapping. - The frequency of data sets reporting successful eradication of a non-native fish species using passive netting/trapping was similar as for electrofishing 634 (i.e., 58\% of data sets each) (Fig. 6f). All but one study using passive removal measures 
alone in an attempt to eradicate a non-native fish species used monofilament gill nets

636 with varying mesh sizes (i.e., 10-100-mm). Lozano-Vilano et al. (2006) was the only study that used standard minnow traps to target spotted jewelfish (Hemichromis guttatus)

638 in Mexico. There were no differences in reported effectiveness among regions. Fifty percent of the data sets were from a single study (Knapp et al. 2007) which targeted non640 native trout (Oncorhynchus sp., Salvelinus sp.) for removal from a series of mountain lakes in California, USA. Other studies were conducted in alpine lakes in Alberta

642 Canada, Washington, USA, and another in California. Two other removal studies were from a lake complex in Waikato, New Zealand and a pond in Coahuila Mexico.

644 There did not appear to be any patterns associated with reported factors and eradication effectiveness using passive measures. Most passive netting/trapping studies

646 have been conducted in relatively small [i.e., $<90000 \mathrm{~m}^{2}$ (or 9 ha)], shallow [i.e., $\leq 11 \mathrm{~m}$ ] lenthic systems. All studies employed a BA study design, and the passive netting/trapping 648 measure was applied for more than 1 year (range: 2-6 years). In most eradication attempts using passive removal measures, intensive, continuous netting was conducted throughout 650 the year ( $75 \%$ of data sets). For the studies that did not conduct continuous netting/trapping, the number of removal treatments was 2 (Neilson et al. 2004) and 17

652 times (Lozano-Vilano et al. 2006) with vague information reported in another (i.e., Hoffman et al. 2004: "gill nets were placed in the lake from one to three days, once to 654 several times a field season"). Post-treatment sampling ranged from 0 to 5 years after the last treatment or until fish were no longer captured. Despite the variability in the number 656 of during and after treatment years, and the removal effort used for removals, there were no obvious patterns between these variables and the effectiveness of passive removal 
658 measures. Furthermore, containment measures were present in only 3 data sets, all in the form of natural barriers (Cony Lake: Knapp et al. 2007; Maul Lake: Knapp and Matthews 660 1998). All outcome categories were semi-quantitative with the exception of two studies that reported quantitative approximations (Parker et al. 2001) and quantitative (Neilson et

662 al. 2004) outcome information for comparator and intervention groups. See Table S11 for summary characteristics and results of studies implementing passive netting/trapping 664 alone for eradication of a non-native fish species.

\section{Physical removal for population size control}

Nearly $28 \%$ of data sets implemented a single physical removal measure for population

668 size control of a non-native fish. Three general categories of physical removal measures were used: (1) electrofishing (15 studies, 34 data sets); (2) passive netting (4 studies, 4

670 data sets), and (3) active netting (3 studies, 6 data sets). Study validities for effective electrofishing data sets for population control were mostly very low or low assessments;

672 however, there were a number of medium study validity assessments across effectiveness ratings for electrofishing (Fig. $6 g$ ). All active netting data sets, and 50\% of the passive

674 netting data sets, were assessed as low study validity (Fig. $6 h$ and $i$ ).

676 Electrofishing. - Electrofishing was reported to be effective in reducing population size of a non-native fish in 56\% of data sets (Fig. $6 g$ ). Studies using electrofishing alone in

678 attempting to control non-native fish population size used either boat or back-pack electrofishing equipment ( $41 \%$ and $56 \%$ of data sets, respectively). All but three studies

680 were conducted in the USA. 
No discernible patterns were found between population control effectiveness and 682 factors that could cause variation. Evaluations were conducted in mostly lotic systems such as rivers ( $53 \%$ of data sets) and creeks/streams (41\%), and one study each in a weir

684 (Thuesen et al. 2011) and a canal (Smith et al. 1996). A variety of non-native species were targeted for population control using electrofishing (14 species); the most common

686 being trout species (i.e., rainbow and brook trout with $21 \%$ of data sets each). Similarly, a variety of study designs were used for evaluations of electrofishing, the most frequent 688 design being BA ( $65 \%$ of data sets). Two studies (7 data sets) used a BACI design (Thompson and Rahel 1996; Propst et al. 2015), and three studies (5 data sets) used a CI 690 design (Coggins 2008; Firehammer et al. 2009).

Unlike eradication-oriented studies, we did not observe a positive relationship

692 between the number of effective data sets and the number of electrofishing treatments in population control studies. Furthermore, for all studies but one, there were no post-

694 treatment sampling, meaning that there were always fish captured/ removed from each electrofishing treatment and/or that a different main intervention was never used at a later

696 period to evaluate the effectiveness of electrofishing treatments in reducing population size of the target species. In the single study that did include after treatment monitoring,

698 Meyer et al. (2006) returned to compare abundance and population dynamics of brook trout present after 3 years after treatment to the population in the treatment years.

There were three studies ( 5 data sets) that investigated the effectiveness of electrofishing for both eradication or population control, or that had unclear objective 702 statements. As previously noted, when eradication was considered as the primary goal in these studies, all were found to be ineffective (see Table S10). However, when population 
704 control was considered, two of these same studies (4 data sets) were found to be effective in reducing populations size (Thompson and Rahel 1996; Caudron and Champigneulle

706 2011); only one study was found to be ineffective for both eradication and population control (i.e., Meyer et al. 2006).

708 There were a number of electrofishing studies rated as partly effective in reducing population size of a non-native fish ( $35 \%$ of the data sets). In a few of these cases,

710 reductions in abundance were observed in some but not all waterbodies (or sections) (e.g., Franssen et al. 2014), or projects were still considered on-going (e.g., Scoppettone

712 et al. 2012). For other studies, although a reduction in population size was reported, either compensatory reproduction of mature fish that survived removal efforts from previous

714 years (e.g., Carmona-Catot et al. 2010) or immigration and recruitment pulses after treatment, subsequently resulted in increased numbers of younger fish (e.g., Saunders et

716 al. 2015). Furthermore, although declines in non-native fish abundance with removal efforts were observed in some studies, the efficacy of the electrofishing removal was

718 potentially confounded by external(s) systemic decline witnessed in comparator groups (e.g., Coggins 2008). See Table S12 for summary characteristics and results of studies

720 implementing electrofishing alone for population control of a non-native fish species.

722 Passive and active netting. - Passive and active netting measures were reported effective in reducing population size of a non-native fish in $25 \%$, and $67 \%$ of data sets,

724 respectively. Both netting categories had relatively small sample sizes compared to the number of electrofishing cases (Fig. $6 h$ and $i$ ), severely limiting analysis of the

726 effectiveness of these measures for population control. Passive removal measures used to reduce population size included fyke $(8-16 \mathrm{~mm})$, and gill nets $(10-38 \mathrm{~mm})$. Seining was 
728 the only active removal measure used (i.e., $4.8 \mathrm{~mm}$ mesh sizes and conventional commercial seining using 35-mm square mesh size guided by Judas fish). Seventy

730 percent of the data sets (4 studies) were conducted in the USA, with two studies in Europe, and a single study on a lake complex in Waikato, New Zealand. Passive and

732 active removal measures have been investigated in a range of lake sizes $(2500-120,000$ $\left.\mathrm{m}^{2}\right)$, and in two rivers $(80.5-\mathrm{km}$ reach; and three 16-km long reaches; Trammel et al.

734 2004). Both ineffective population control data sets were from this single study on rivers [93]. Only two studies employed a BACI study design (Trammel et al. 2004; Britton et al.

736 2010); all others used a BA design. Passive and active netting was applied for 1 to 20 years; however, this variable did not appear to be related to population control

738 effectiveness. None of the passive or active removal measures were used continuously throughout the year, with $60 \%$ of the data sets conducted in a single season. From the

740 available information, the number of removal treatments ranged from 1-15; with limited information reported in longest duration study (i.e., Bigelow et al. 2017). Interestingly,

742 the single study with the greatest number of treatments was found to be ineffective in reducing population size. Trammel et al. (2004) suggested that although a reduction of

744 non-native cyprinids was observed, this reduction was quickly offset by reproduction and that many smaller sized fish escaped through the seine nets. There were no apparent

746 patterns between passive or active netting effectiveness for population control and the presence of a containment measure(s), or outcome category. See Table S13 for summary

748 characteristics and results of studies implementing passive or active netting alone for population control of a non-native fish species. 
Combinations of physical removals for eradication. - A few studies have combined

752 various physical removal measures in an attempt to eradicate a non-native fish (6 studies), with $50 \%$ of them reporting successful eradications. Most of the included

754 studies appear to be conducted in relatively larger lakes than the majority of the previously discussed studies [range: $23,400-53,100,00 \mathrm{~m}^{2}$ (or $2.34-531$ ha)]. The

756 number of different types of measures used in combination was 2 or 5 , both occurring in three studies each. All of these studies used at least one form of passive netting (i.e.,

758 gill, fyke, seine nets) or trapping (i.e., minnow or plastic bottle traps), and electrofishing.

760 Keeping in mind the small number of studies, there did not appear to be a pattern between the number of measures used or the combination of measures and eradication

762 effectiveness. Reported information was limited on the number of applications and the time between implementation of each of the measures. From what information could be

764 extracted, the combination of measures were implemented in relatively short duration of each other, if not simultaneously. Note here again, however, the two studies that

766 investigated the effectiveness of a combination of physical removal methods for either eradication or population control, or that had unclear objective statements, were both

768 found to be ineffective for eradication. See Table S14 for summary characteristics and results of studies implementing combinations of physical removal measures for

770 eradication of a non-native fish species.

772 Combinations of physical removals for population size control. - There were greater number of studies using a combination of physical removal measures for non-native fish 
774 population control than for eradication (19 data sets, 15 studies). A combination of physical removal measures was reported effective in reducing population size of a non-

776 native fish in $32 \%$ of data sets. Studies using multiple physical removal measures for population control were widely conducted across locales and waterbody types, and

778 targeted a variety of non-native fish species; however, these factors did not appear to be associated with effectiveness. The number of different types of measures used in

780 combination ranged from 2 to 5 ; the majority of which used two physical removal measures ( $74 \%$ of data sets). Combinations of measures were applied simultaneously.

782 There did not appear to be a pattern between the number of measures used or the combination of measures, and population control effectiveness. See Table S15 for

784 summary characteristics and results of studies implementing combinations of physical removal measures for population size control of a non-native fish species.

\section{Biological treatment}

Information on the effectiveness of biological control measures to eradicate or control

790 population size of non-native fish is very limited. Only a single study included in the review used a biological control measure alone for removal of a non-native fish species.

792 Koenig et al. (2015) investigated the effectiveness of introducing sterile tiger muskellunge (i.e., Northern pike Esox lucius x Muskellunge E. masquinongy) to eradicate

794 or suppress brook trout populations in alpine lakes in Idaho, USA. Using a BACI study design, Koenig et al. (2015) compared CPUE from 13 stocked lakes - each stocked once

796 and at a constant density of $40 \mathrm{fish} / \mathrm{ha}$ - to four control lakes $4-5$ years after predator 
stocking. Complete eradication occurred in 4 of the 13 lakes within 2-5 years after

798 stocking, and declines in CPUE were seen for both treatment and control lakes, resulting in partial effectiveness ratings for both eradication and population control (Fig. $6 j$ and $k$ ).

800 This study was assessed as having medium study validity.

\section{Harvest regime treatment}

Very few studies on harvest regime measures were included in the review (Fig. 6l). Two

804 forms of intentional over-fishing for population control of target species were evaluated in relatively large water systems in the USA using: (1) gill, trammel and hoop nets, and

806 seine hauls (MacNamara et al. 2016), and (2) angling (Larson et al. 1986). During a 3year treatment period (c. 340 crew-days per year), MacNamara et al. (2016) reported that

808 the overall density of silver (Hypophthalmichthys molitrix) and bighead carp (H. nobilis) decreased by over $40 \%$ and subsequently remained stable in different reaches of the

810 Upper Illinois River, USA. In a comparatively short-duration (9-week) evaluation of an experimental fishery in Tennessee, USA, angling was found to reduce the density of non-

812 native rainbow trout (Larson et al. 1986). However, the fishery was found to have minor immediate effect on the smallest size class of fish.

\section{Environmental treatment}

816 Two low validity studies used an environment measure alone, in the form of water body dewatering, for removal of a non-native fish species (Fig. $6 m$ and $n$ ). These studies found 818 that one attempt at pond dewatering was ineffective in eradicating the topmouth gudgeon (Pseudorasbora parva) in North Yorkshire, England (Pond 3: Britton et al. 2008), but 
820 effective in reducing the abundance of Eastern mosquitofish (Gambusia holbrooki) within multiple ponds in New South Wales, Australia.

\section{Combinations of different removal measures}

824 Nearly $13 \%$ of the data sets are evaluations of various combinations of removal measures (20 data sets from 16 studies). Comparisons of the effectiveness within, or across these

826 combinations are difficult because it is not always possible to determine whether successful eradication or population control is a result of a single intervention or the

828 cumulative effects of two or more interventions within that combination. This is especially true if applications are conducted simultaneously or in close temporal

830 proximity of each other, and/or if limited details are provided to determine otherwise. Nonetheless, some general patterns can be seen from the studies. See Table S16 for

832 summary characteristics and results of studies implementing various combinations of removal measures for population control or eradication of a non-native fish species

834 Although limited in number, there are studies showing effective eradication with lake dewatering in conjunction with chemical treatment. Successful eradication of non-

836 native fish using the combination of dewatering of lakes/ponds followed shortly after by one chemical application of lime was reported in two studies (David 2003; Britton et al.

838 2008). For both studies, post-monitoring was reportedly conducted shortly after liming had been implemented. In a third study, Inland Fisheries Service (2005) reported the

840 ineffectiveness of two predatory fish species (rainbow and brown trout) to eradicate Eastern mosquitofish in a reservoir in Tasmania. Although very little details are provided 842 - resulting in a very low study validity assessment-, after the biological control attempt 
failed, the reservoir was subsequently dewatered and treated with a chemical (the type

844 unstated) that was reported to be successful in eradicating the non-native population.

Mixed results have been reported for the effectiveness of stocking predatory fish

846 for population control following unsuccessful eradication attempts using rotenone. Ward et al. (2008) evaluated the effectiveness of utilizing Bear Lake cutthroat trout

848 (Oncorhynchus clarkii utah) to control Utah chub (Gila atraria) populations in a reservoir in Utah, USA, and over a 16-year period, predacious cutthroat trout were

850 effective in controlling the chub population. Conversely, Michaels (2011) found that a large piscivore population, primarily largemouth bass (Micropterus salmoides), were

852 ineffective in controlling common carp numbers in Illinois, USA. Both studies were classified as very low study validity as a result of deficient BA study designs.

854 Studies implementing a combination of physical and harvest regime measures also had mixed results for removal effectiveness. In all three cases, timing of applications for 856 the different treatments overlapped. Earle et al. (2009) reported decreased abundance of brook trout after 11 years of selective harvest by anglers and electrofishing treatments.

858 Using these same treatments, Evangelista et al. (2015) found that removal effort did not affect the total abundance of non-native North American pumpkinseed (Lepomis

860 gibbosus) in France. Furthermore, an intensive study in Miramichi Lake, New Brunswick, Canada found that a combination of multiple physical removal measures and

862 harvesting reduced the size of a smallmouth bass population (Micropterus dolomieu), but complete eradication was not achieved (DFO 2013).

864 The most frequent combination of removal measures included physical and chemical treatments to eradicate a non-native fish species $(50 \%$ of the combination data 
866 set). Eradication was reported effective in $60 \%$ of these cases. Often physical removal measure(s) were used prior to chemical treatment(s) to minimize injury or mortality to 868 native species present in the study waterbody, and/or remove as many non-natives as possible (e.g., Lintermans and Rutzou 1990; Lintermans and Bourne 2011); most of these

870 attempted eradications were successful (but see Lintermans and Rutzou (1990) which reported eradications in some but not all ponds due to dense submerged weed beds and

872 fringing emergent vegetation preventing mixing of rotenone). Buktenica et al. (2013), for example, reported a successful eradication of brook trout from Sun Creek, Oregon, USA,

874 after 14 years of using electrofishing in the smaller headwaters of the creek, and the combination of electrofishing and antimycin treatments (5 applications between 1992-

876 2005) in the larger downstream reaches. The use of trap-net electrofishing (i.e., customdesigned net constructed of 0.95 -cm nylon mesh including two wings directing fish,

878 herded by backpack electrofishers, through a fyke tunnel into a net bag) was reportedly very effective for removing brook trout and salvaging the native bull trout (Salvelinus 880 confluentus) prior to chemical treatments (Buktenica et al. 2013). In another situation, chemical treatment with rotenone was applied first to Elk Creek, Yellowstone National

882 Park, USA - a water system devoid of any native fish - and was followed by electrofishing (Ertel et al. 2017). Both treatments were applied once a year for three years

884 resulting in the successful eradication of brook trout. Only one study reported an ineffective eradication attempt using the combination of physical and chemical measures.

886 In a rapid response to round goby (Neogobius melanostomus) in Pefferlaw Brook, Ontario, Canada, Dimond et al. (2010) reported a failed attempt at eradication after using 888 a single treatment of rotenone. Because an additional treatment of rotenone was not 
possible because the permit was limited to a single application, monitoring and removal

890 intensified through the use of passive trapping, seining, electrofishing and angling; however, their attempts at eradication were unsuccessful and efforts then shifted to

892 monitoring the spread of the non-native (Dimond et al. 2010).

Lastly, combinations involving physical and environmental measures have shown

894 mixed results. Beatty and Morgan (2017) reported complete eradication of European perch from a reservoir in Western Australia using a combination of gillnetting and

896 seining, and reservoir dewatering. In a different reservoir in Western Australia, however, Molony et al. (2005) reported unsuccessful eradication but effective reduction in

898 abundance of European perch using a combination of gillnetting to reduce abundance of perch prior to dewatering, followed by a concussive technique using emulsion explosives.

\section{Discussion}

\section{Implications for Management}

Here, we present what we believe to be the first comprehensive review that

904 systematically evaluates the quality and quantity of the existing literature base on the topic of the effectiveness of different non-native fish eradication and control methods.

906 Although much of the evidence is based on poorly documented studies with inadequate experimental designs, and therefore considerable caution is warranted, our review

908 nevertheless highlights some general points of consideration for management agencies and researchers.

910 First, when the goal of a management study is non-native fish eradication, chemical treatments had relatively high success rates (antimycin 75\%; rotenone $89 \%$ ) 
912 compared to other interventions applied. Rotenone, in particular, was more commonly and widely applied globally than any other intervention measure for eradication, and

914 often only required one application (Table S9). Study evaluations of electrofishing and passive removal measures showed successful eradication is possible $(58 \%$ each

916 respectively); however, intensive effort is often required with multiple treatments over a number of years (Table S10 and S11). Furthermore, effectiveness of electrofishing

918 studies may be improved by having explicitly stated management objectives with study designs developed with those specific target objectives in mind. Although various

920 combinations of removal measures in an attempt to eradicate a non-native fish have been used, many of these combinations have been applied in relatively few studies. The most

922 effective combination with the most available data is the combination of physical and chemical measures (effective in 6 of 10 data sets; Table S16).

924 Second, when the goal of a management project is to control non-native fish population size, the effectiveness of different removal measures was quite variable with

926 limited identifiable reasons for such variation. Of the studies with sufficient information, electrofishing had the highest success for population size control (56\% of data sets);

928 however, no discernible patterns could be found to explain variation in population control effectiveness (Table S12). Relatively few studies have been conducted on single passive

930 and active netting measures, limiting adequate comparisons of effectiveness. Studies using multiple physical removal measures for population control were widely conducted

932 across locales and waterbody types, and targeted a variety of non-native fish species; however, results showed a relatively low success rate (32\% of data sets). 
934 Finally, other removal techniques besides physical and chemical measures have been used in attempt to remove non-native fish from freshwater ecosystems, but they

936 were comparatively under-represented in the available literature base. These include, either alone or in combination with other techniques - biological control, harvest

938 regimes, or water-level management measures.

\section{Implications for Research}

We believe one of the most important implications for researchers (and managers) is that

942 many previously conducted projects have likely been undocumented. This failure to document and/or share knowledge on past efforts has undoubtedly come at a cost of lost

944 learning opportunities, and wasted resources across jurisdictions. It became apparent through discussions with our advisory team and public engagement that much of the

946 transfer of knowledge happens through informal discussion between networks of colleagues. Transfer of knowledge through informal networks is most certainly of value

948 and should absolutely continue; however, knowledge transfer would be enhanced if the information is disseminated in a manner that ensures it will be permanently archived (in

950 accessible formats) and more broadly distributed to those who require the information.

Failure to document and/or share knowledge on past efforts is not unique to our

952 review topic (e.g., Davis et al. 2008; Ramstead et al. 2012; Lintermans 2013), and further underscores the need to make such information broadly available. One approach that

954 might be of benefit is the use of journals that encourage submission of papers that document the outcomes of management practice (or field interventions) such as case

956 study reports (e.g., Journal of Fish and Wildlife Management, Restoration Ecology, 
Environmental Management). Another approach could include forming collaborations

958 between practitioners and scientists from universities, government agencies, or other organizations that may have more time and resources to help disseminate the information

960 (Ramstead et al. 2012).

Our review highlights that there is still considerable room for improvement in our

962 evaluations of non-native fish removal methods. The current evidence base is dominated by poorly documented studies with inadequate experimental designs; an observation that

964 has been noted in previous reviews on this topic (Meronek et al. 1996; Corfield et al. 2007; Ayres and Clunie 2010). This may, in large part, be a result of the general approach

966 taken with non-native fish management which is based on site-specific problem solving, and as such, relatively few studies incorporate replicated and controlled investigations

968 with rigorous, long-term quantitative monitoring. Because of time and resource constraints, an adaptive management approach is often implemented, whereby the

970 performance metric becomes the reduction in non-native fish abundance. As Corfield et al. (2007) noted, however, this approach is limited because measures of fish population

972 size or the response of impacted species/communities are rarely used, and the level of control necessary to achieve desired goals remains unknown.

$974 \quad$ We also acknowledge there can be operational realities that are not always conducive to conducting robust research projects (e.g., repeated visits to isolated study

976 locations, finding suitable analogous controls in close proximity within a study area), or ethical issues that might prevent activities that are harmful or inappropriate for species

978 conservation (e.g., monitoring control sites where non-native fish are known to be present and possibly threatening native populations and not applying a removal measure). 
980 Nevertheless, to improve our knowledge on when, where, and how non-native fish removal programs should be implemented, we need to modify our approach to evaluating

982 the effectiveness of removal measures. In this regard, we provide a number of recommendations for future studies (see Table A2). Overall, explicitly stated objectives,

984 better data reporting, study designs that (when possible and appropriate) incorporate experimentation into the process, use of quantitative outcome measures, and long-term

986 assessments of removal methods are recommended. However, incorporating such recommendations will require greater funding from management agencies.

988 There are a number of knowledge gaps on the effectiveness of non-native fish removal methods that deserve further study. First, while previous studies have

990 underscored variables that can affect the success of different removal measures [e.g., habitat complexity, physical water properties, and species-specific factors (e.g., Kolar et

992 al. 2010; Britton et al. 2011b)], given the complexities of the natural environment, interactions between numerous variables makes determination of relationships between a

994 single factor and outcome challenging. The lack of information reported on key environmental and methodological variables precluded an assessment of the effect of

996 these sources of heterogeneity in a robust manner. Furthermore, even when reported, there was often not enough variation in values of the variables to determine whether they

998 influenced the effectiveness of removal measures. For example, all electrofishing evaluations were conducted in lotic systems, mostly smaller creeks/streams, and in one

1000 relatively larger, but simple in morphology, river study. Furthermore, most single passive netting studies for non-native fish eradication have been conducted in relatively small 1002 [i.e., $<90,000 \mathrm{~m}^{2}$ (or 9 ha)], shallow [i.e., $\leq 11 \mathrm{~m}$ ] lentic systems (Table S11). Second, 
there was an insufficient number of studies that investigated the use of biological control,

1004 harvest regime measures, or water-level management to draw meaningful conclusions on their effectiveness for non-native fish removal. To better inform management decisions,

1006 we need to improve research and data reporting for a broader range of removal measures. Third, the majority of the research has focused on a small number of fish species. As we

1008 continue to become globalized, the potential for invasion of non-native fish is real via one of the many invasion pathways. Being able to identify approaches that are most effective

1010 for a given species would be desirable. Similarly, there is little research on understanding the phenotypic characteristics of individuals within a population that fail to be eradicated.

1012 Do those individuals exhibit a particular behaviour (e.g., preference for deep water; see Sih et al. 2012) or have a particular physiology (e.g., metabolic rate or physiological

1014 capacity; see Lennox et al. 2015) that makes them less vulnerable to eradication or control? Knowing such information could provide insight into how to potentially adjust

1016 eradication and control efforts to better target all individuals in a given target population. These topics are at the fore of invasive species science and are being explored for sea

1018 lamprey in the context of pesticide resistance (Dunlop et al. 2017).

To facilitate the knowledge base required for developing more effective removal 1020 methods, we have the following recommendations for reporting of future studies. First, authors should provide raw data in an appendix or data archiving site. Outcome data

1022 should be reported for each year before and after implementation of a removal measure, and for each control and impact site separately. In other words, outcome data should not

1024 be combined across years and/or sites and authors should clearly distinguish before, during, and after intervention implementation periods, for each intervention method 
1026 applied. Outcome data should also be recorded separately for each species or species group wherever possible. Second, authors should include information on: (i) study

1028 locations (e.g., waterbody type, waterbody area, depth, open or closed waterbody system, $\mathrm{pH}$, temperature, discharge, plant density or coverage, canopy coverage, waterbody

1030 accessibility, and presence of containment measures prior to or during study), (ii) speciesspecific information (e.g., habitat preferences, time since non-native introduction or

1032 detection, vectors of introduction, and the extent that the population is established), (iii) the study design (e.g., outcome sampling method, outcome measure used, and duration of

1034 outcome sampling), (iv) interventions (e.g., type of removal measure(s), number of applications per intervention, number of different interventions, timing of application in

1036 relation to other applied interventions, if $>1$ intervention, method of application, and seasonality of intervention application), and (v) the overall project (e.g., level of

1038 intervention maintenance, if applicable, and project costs). If this information is already available in another published study, authors should direct readers to that information. If

1040 we are to further our understanding of removal measure effectiveness, it is essential we make all monitoring data available and provide comprehensive information on study

1042 locations, study design, intervention types and details of their application, and the outcomes used and how they were measured.

1044

\section{Review limitations}

1046 There were a number of limitations of this review. These limitations fall into three general (but interrelated) categories: (1) lack of high quality (low bias) studies; (2) lack of 
1048 information reported on key environmental and methodological variables; (3) inaccessibility of data.

First, there was a paucity of studies designed to address our primary question in a robust, quantitative manner. Over $75 \%$ of removal projects were considered to have very

1052 low or low study validity, warranting considerable caution when interpreting removal measure effectiveness. The major causes for these classifications were due to: (1) low

1054 spatial/temporal replication (i.e., $47 \%$ of the included data sets had measurements for either one year before and one year after treatment for BA designs, or one control site and

1056 one impact site for CI designs); inadequate replication effectively limited effect size estimation for meta-analytical purposes for these data sets; (2) the use of a qualitative 1058 outcome measure for the comparator group and/or intervention group (i.e., $53 \%$ of data sets), limited our ability to use standard effect size estimates, and (3) relatively short 1060 duration of post-treatment monitoring (e.g., 54\% of data sets did not conduct any 'true' post-treatment monitoring; of those that did, $49 \%$ only did so $\leq 1$ year after the 1062 intervention was applied).

Second, missing information in relation to study methodology and environmental

1064 characteristics was a common issue. Key details were often not reported, or not easily identifiable, in relation to the date of intervention application when more than one type of

1066 intervention was applied, the number of applications, and accurate information on time since invasion. Similarly, information on various environmental variables related to the 1068 physical and chemical characteristics of the study location(s) were often not reported (e.g., depth, temperature, and whether the study waterbody was open or closed were 1070 reported in $38 \%, 20 \%, 54 \%$ of data sets, respectively). Inadequate data reporting severely 
limited our ability to address one of our main review questions: 'What factors influence

1072 the effectiveness of each type of removal method and in what context is each technique most effective?'.

1074 Lastly, we believe one of the greatest limitations of this review is that many previous studies have not been documented. Despite our best efforts to retrieve as much

1076 published and grey literature as possible, including discussions with our advisory team and public engagement over the course of this review, studies with limited, or a complete

1078 lack of documentation were common. It is difficult to speculate whether and how our results may be biased without inclusion of these studies; however, we did observe a

1080 higher ratio of effective to ineffective removal attempts from published articles compared to unpublished documents (6:1 and 3.6:1, respectively). If many ineffective removal

1082 attempts went unreported, our results may be biased by a tendency to report more frequently on effective studies. Although the "file drawer effect" may be partly

1084 responsible for this pattern, another potential explanation is that most removal studies are associated with management actions rather than research experiments. Furthermore, most management practitioners are not rewarded for publishing findings nor provided the support to do so.

In addition to possible publication bias, there were some geographical biases in the data. The majority of studies were from North American (62\% of studies), in a particular 1090 USA (51\% of studies), potentially limiting interpretation of review results to other geographic regions.

\section{Conclusions}


1094 Our review highlights several key points of consideration for both the management of non-native fish and research on non-native fish eradication and population control

1096 methods. First, the evidence base was dominated by poorly documented studies with inadequate experimental designs. For proper evaluation and interpretation of the efficacy

1098 of non-native fish management techniques, programs should have explicitly stated objectives, and study designs that (when possible and appropriate) incorporate replicated

1100 and controlled investigations with rigorous, long-term quantitative monitoring (i.e., measures of fish population size both before and after treatment sampling rather than

1102 presence/absence data) (Table A2). Second, insufficient data reporting on important environmental and methodological variables severely limited our ability to make strong

1104 conclusions about the relationships between non-native fish abundance and different methods of eradication and population control, or the factors that influence the overall

1106 success rate of each type of method. To facilitate the knowledge base required for developing more effective removal methods, we need to improve data reporting by

1108 providing comprehensive information on study locations, study design, intervention types and details of their application, and the outcomes used and how they were measured.

1110 Lastly, our review would have been stronger if the results of more evaluations of removal measures had been made more widely available. Assessments of fish eradication and

1112 population control methods should be disseminated in a manner that ensures they will be permanently archived and more broadly accessed by those who require the information. 


\section{Acknowledgements}

1118 The study was primarily supported by Parks Canada. Additional support is provided by the Natural Science and Engineering Research Council of Canada, The Canada Research

1120 Chairs Program, and Carleton University. The authors would like to thank several reviewers and collaborators who provided valuable insights to strengthen this review

1122 including: Parks Canada staff including Mark Taylor, Bill Hunt, Scott Parker, Shelley Humphries, and Chris McCarthy. We also thank Kim Birnie-Gauvin for help with article

1124 screening and Petra Szekeres for early meta-data extraction. Any use of trade, firm or product names is for descriptive purposes only and does not imply endorsement by the U.S.

1126 Government.

1128 References

Ayres, R., and Clunie, P. 2010. Management of freshwater fish incursions: a review. PestSmart Toolkit publication, Invasive Animals Cooperative Research Centre, Canberra, Australia.

1132 Baker, G., Darby, N., and Williams, T. 2010. Bonneville cutthroat trout restoration project: Great Basin National Park. Department of the Interior, National Park Service, Natural Resources Program Center.

Beamesderfer, R.C. 2000. Managing fish predators and competitors: deciding when intervention is effective and appropriate. Fisheries, 25(6):18-23. doi:10.1577/15488446(2000)025<0018:MFPACD>2.0.CO;2. 
1138 Beatty, S.J., and Morgan, D.L. 2017. Rapid proliferation of an endemic galaxiid following eradication of an alien piscivore (Perca fluviatilis) from a reservoir. J. Fish Biol. 90(3):1090-1097. doi:10.1111/jfb.13214.

Bigelow, P.E., Doepke, P.D., Bertel, B.D., Guy, C.S., Syslo, J.M., and Koel, T.M. 2017. Suppressing non-native lake trout to restore native cutthroat trout in Yellowstone Lake. Yellowstone Science, 25(1):53-59.

1144 Boogaard, M.A., Bills, T.D., Selgeby, J.H., and Johnson, D.A. 1996. Evaluation of piscicides for control of ruffe. N. Am. J. Fish. Manage. 16(3):600-607. doi:10.1577/1548-8675(1996)016<0600:EOPFCO >2.3.CO;2.

Britton, J.R., and Brazier, M. 2006. Eradicating the invasive topmouth gudgeon, Pseudorasbora parva, from a recreational fishery in northern England. Fisheries Manag. Ecol. 13(5):329-335. doi:10.1111/j.1365-2400.2006.00510.x.

1150 Britton, J.R., Brazier, M., Davies, G.D., and Chare, S.I. 2008. Case studies on eradicating the Asiatic cyprinid Pseudorasbora parva from fishing lakes in England to prevent their riverine dispersal. Aquat. Conserv. 18(6):867-876. doi:10.1002/aqc.919.

Britton, J.R., Davies, G.D., and Brazier, M. 2010. Towards the successful control of the invasive Pseudorasbora parva in the UK. Biol. Invasions, 12(1):125-131. doi:10.1007/s10530-009-9436-1.

1156 Britton, J.R., Copp, G.H., Brazier, M., and Davies, G.D. 2011a. A modular assessment tool for managing introduced fishes according to risks of species and their 1158 populations, and impacts of management actions. Biol. Invasions, 13(12):28472860. doi:10.1007/s10530-011-9967-0. 
1160 Britton, J.R., Gozlan, R.E., and Copp, G.H. 2011b. Managing non-native fish in the environment. Fish Fish. 12(3):256-274. doi:10.1111/j.1467-2979.2010.00390.x.

1162 Buhle, E.R., Margolis, M., and Ruesink, J.L. 2005. Bang for buck: cost effective control of invasive species with different life histories. Ecol. Econ. 52(3):355-366. doi:10.1016/j.ecolecon.2004.07.018.

Buktenica, M.W., Hering, D.K., Girdner, S.F., Mahoney, B.D., and Rosenlund, B.D. 2013. Eradication of nonnative brook trout with electrofishing and antimycin-A and the response of a remnant Bull Trout population. N. Am. J. Fish. Manage. 33(1):117-129. doi:10.1080/02755947.2012.747452.

Carmona-Catot, G., Moyle, P.B., Aparicio, E., Crain, P.K., Thompson, L.C., and GarcíaBerthou, E. 2010. brook trout removal as a conservation tool to restore Eagle Lake rainbow trout. N. Am. J. Fish. Manage. 30(5):1315-1323. doi:10.1577/M10-077.1.

1172 Caudron, A., and Champigneulle, A. 2011. Multiple electrofishing as a mitigate tool for removing nonnative Atlantic brown trout (Salmo trutta L.) threatening a native Mediterranean brown trout population. Eur. J. Wildlife Res. 57(3):575-583. doi:10.1007/s10344-010-0468-8.

1176 [CEE] Collaboration for Environmental Evidence. 2013. Guidelines for systematic review and evidence synthesis in environmental management. Version 4.2. Environ. Evid. [online] Available from http://environmentalevidence.org/wpcontent/uploads/2014/06/Review-guidelines-version-4.2-finalPRINT.pdf [accessed $1180 \quad 26$ Feb 2015].

[CEE] Collaboration for Environmental Evidence. 2018. Guidelines and standards for evidence synthesis in environmental management. Version 5.0. Available from 
http://www.environmentalevidence.org/information-for-authors. [accessed July 28 1184 2018].

Clarke Murray, C., Pakhomov, E.A., and Therriault, T.W. 2011. Recreational boating: a large unregulated vector transporting marine invasive species. Divers. Distrib. 17(6):1161-1172. doi: 10.1111/j.1472-4642.2011.00798.x.

1188 Clearwater, S.J., Hickey, C.W., and Martin, M.L. 2008. Overview of potential piscicides and molluscicides for controlling aquatic pest species in New Zealand. Science for Conservation, 283:1-74.

Closs, G.P., Ludgate, B., and Goldsmith, R.J. 2001. Controlling European perch (Perca fluviatilis): lessons from an experimental removal. In Proceedings of a workshop entitled "Managing invasive freshwater fish in New Zealand", Hamilton, New Zealand, 10-12 May 2001. Hosted Department of Conservation, New Zealand. pp. $37-48$.

1196 Coggins, L.G. Jr. 2008. Active adaptive management for native fish conservation in the Grand Canyon: implementation and evaluation. Doctoral dissertation, University of $1198 \quad$ Florida, Gainesville, FL.

Cooke, S.J, Wesch, S., Donaldson, L.A., Wilson, A.D.M., and Haddaway, N.R. 2017. A call for evidence-based conservation and management of fisheries and aquatic resources. Fisheries. 42(3):143-149. doi: 10.1080/03632415.2017.1276343.

1202 Copp, G.H., Russell, I.C., Peeler, E.J., Gherardi, F., Tricarico, E., Macleod, A., Cowx, I.G., Nunn, A.D., Occhipinti-Ambrogi, A., Savini, D., Mumford, J., and Britton, 1204 J.R. 2016. European non-native species in aquaculture risk analysis scheme - a 
summary of assessment protocols and decision support tools for use of alien species

1206 in aquaculture. Fish. Manag. Ecol. 23(1):1-11. doi: 10.1111/fme.12074.

Corfield, J., Diggles, B., Jubb, C., McDowall, R.M., Moore, A., Richards, A., and Rowe,

1208 D.K. 2007. Draft final report for the project Review of the impacts of introduced aquarium fish species that have established wild populations in Australia. Prepared

1210 for the Australian Government Department of the Environment and Water Resources, Canberra, Australia.

1212 David, B. 2003. Eradication of koi carp from an enclosed pond in Houhora. Department of Conservation Internal Working Report. Department of Conservation, Hamilton 1214 (unpublished report).

Davis, G.S., and Britton, J.R. 2015. Assessing the efficacy and ecology of biocontrol and biomanipulation for managing invasive pest fish. J. Appl. Ecol. 52(5):1264-1273. doi: $10.1111 / 1365-2664.12488$.

1218 Davis, Z.G., Tyler, C., Stewart, G.B., and Pullin, A.S. 2008. Are current management recommendations for saproxylic invertebrates effective? a systematic review. Biodivers. Conserv. 17(1):209-234. doi:10.1007/s10531-007-9242-y.

[DFO] Department of Fisheries and Oceans Canada. 2013. Review of control and eradication activities in 2010 to 2012 targeting Smallmouth Bass in Miramichi Lake, New Brunswick. DFO Can. Sci. Advis. Sec. Sci. Resp. 2013/012.

1224 Dimond, P.E., Mandrak, N.E., and Brownson, B. 2010. Summary of the rapid response to round goby (Neogobius melanostomus) in Pefferlaw Brook with an evaluation of 1226 the national rapid response framework based on the Pefferlaw Brook experience. DFO Can. Sci. Advis. Sec. Res. Doc. 2010/036. vi +33p. 
1228 Donaldson, L.A., and Cooke, S.J. 2016. The effectiveness of non-native fish eradication techniques in freshwater ecosystems: a systematic review protocol. Environ. Evid. 5:12. doi: 10.1186/s13750-016-0063-X.

Dunlop, E.S., McLaughlin, R., Adams, J.V., Jones, M., Birceanu, O., Christie, M.R., Criger, L.A., Hinderer, J.L.M., Hollingworth, R.M., Johnson, N.S., Lantz, S.R., Li, W., Miller, J., Morrison, B.J., Mota-Sanchez, D., Muir, A., Sepúlveda, M.S., Steeves, T., Walter, L., Westman, E., Wirgin, I., and Wilkie, M.P. 2017. Rapid evolution meets invasive species control: the potential for pesticide resistance in sea lamprey. Can. J. Fish. Aquat. Sci. 75(1):152-168. doi: 10.1139/cjfas-2017-0015.

Earle, J.E., Paul, A.J., Stelfox, J.D. 2010. Quirk Creek population estimates and one-pass electrofishing removal of brook trout-2009. Unpublished report, Fish and Wildlife Division, Alberta Sustainable Resource Development, Cochrane, Alberta.

1240 Elkins, A., Barrow, R., and Rochfort, S. 2009. Carp chemical sensing and the potential of natural environmental attractants for control of carp: a review. Environ. Chem. 6(5):357-368. doi: 10.1071/EN09032.

Ertel, B.D., Heim, K.C., Arnold, J.L., Detjens, C.R., and Koel, T.M. 2017. Preservation of native cutthroat trout in northern Yellowstone. Yellowstone Science, 25(1):3541. Available from http://www.nrcresearchpress.com/page/er/authors\#9d [accessed 20 April 2017].

Evangelista, C., Britton, R.J., and Cucherousset, J. 2015. Impacts of invasive fish removal through angling on population characteristics and juvenile growth rate. Ecol. Evol. 5(11):2193-2202. doi:_10.1002/ece3.1471. 
1250 Fausch, K.D., Rieman, B.E., Young, M.K., and Dunham, J.B. 2006. Strategies for conserving native salmonid populations at risk from nonnative fish invasions: tradeoffs in using barriers to upstream movement. General Technical Report RMRS-GTR-174, USDA Forest Service, Rocky Mountain Research Station, Fort 1254 Collins, Colorado.

Finlayson, B.J., Schnick, R.A., Cailteux, R.L., DeMong, L., Horton, W.D., McClay W., 1256 Thompson, C.W., and Tichacek, G. 2000. Rotenone Use in Fisheries Management: Administrative and Technical Guidelines Manual [online]. American Fisheries Society: Maryland, Bethesda, Maryland. Available from http://www.fisheriessociety.org/rotenone/Rotenone_Manual.pdf [accessed July 1260 2015].

Finnoff, D., Shogren, J.F., Leung, B., and Lodge, D. 2007. Take a risk: preferring prevention over control of biological invaders. Ecol. Econ. 62(2):216-222. doi:10.1016/j.ecolecon.2006.03.025.

1264 Firehammer, J.A., Vitale, A.J., and Hallock, S.A. 2009. Implementation of fisheries enhancement opportunities on the Coeur d'Alene Reservation. 2007 Annual Report. Coeur d'Alene Tribe Fish, Water, and Wildlife Program, Portland OR.

Franssen, N.R., Davis, J.E., Ryden, D.W., and Gido, K.B. 2014. Fish community 1268 responses to mechanical removal of nonnative fishes in a large southwestern river. Fisheries, 39(8):352-363. doi:10.1080/03632415.2014.924409.

1270 Fredenberg, W. 2002. Further evidence that lake trout displace bull trout in mountain lakes. Intermt. J. Sci. 8(3):143-152. 
1272 Gaeta, J.W., Hrabik, T.R., Sass, G.C., Roth, B.M., Gilbert, S.T., and Vander Zanden, M.J. 2015. A whole-lake experiment to control invasive rainbow smilt

1274 (Actinoperygii, Osmeridae) via overharvest and food web manipulation.

Hydrobiologia, 745:433-444. doi: 10.1007/s10750-014-1916-3.

1276 Genovesi, P. 2005. Eradication of invasive alien species in Europe: a review. Biol. Invasions. 7(1):127-133. doi: 10.1007/s10530-004-9642-9.

1278 Gozlan, R.E., Whipps, C., Andreou, D., and Arkush, K. 2009. Identification of a rosettelike agent as Sphaerothecum destruens, a multi-host fish pathogen. Int. J. Parasitol. 39(10):1055-1058. doi:10.1016/j.ijpara.2009.04.012.

Gozlan, R.E., Britton, J.R., Cowx, I., and Copp, G. 2010. Current knowledge on nonnative freshwater fish introductions. J. Fish Biol. 76(4):751-786. doi:10.1111/j.1095-8649.2010.02566.x.

1284 Gresswell, R.E. 1991. Use of antimycin for removal of brook trout from a tributary of Yellowstone Lake. Trans. Am. Fish. Soc. 11(1):83-90. doi:10.1577/15488675(1991)011<0083:UOAFRO>2.3.CO;2.

Halfyard, E.A. 2010. A review of the options for the containment, control and eradication of illegally introduced smallmouth bass (Micropterus dolomieu). Fisheries and Oceans Canada, Oceans and Science Branch, Aquatic Resources Division, Gulf Region, Moncton, NB.

Hall, D.A. 1988. The eradication of European carp and goldfish from the Leigh Creek Retention Dam. Safish. 12:15-6. 
Hoffman, R.L., Larson, G.L., and Samora, B. 2004. Responses of Ambystoma gracile to the removal of introduced nonnative fish from a mountain lake. J. Herpetol. 38(4):578-585. doi:10.1670/44-04A.

1296 Hooper, W.C., and Gilbert, J.C. 1978. Goldfish eradication, standing crop estimates of fishes and fisheries management recommendations for a small, mesotrophic New Brunswick lake. Fisheries Management Report No. 6. Fish and Wildlife Branch, Department of Natural Resources, Fredericton, NB, Canada.

Inland Fisheries Service. 2005. Inland Fisheries Service Annual Report 2004-05. Inland Fisheries Service, Moonah, Tasmania.

1302 Knapp, R.A., and Matthews, K.R. 1998. Eradication of nonnative fish by gill netting from a small mountain lake in California. Restor. Ecol. 6(2):207-213. doi:10.1111/j.1526-100X.1998.06212.x.

Knapp, R.A., Boiano, D.M., and Vredenburg, V.T. 2007. Removal of nonnative fish results in population expansion of a declining amphibian (mountain yellow-legged frog, Rana muscosa). Biol. Conserv. 135(1):11-20. doi:10.1016/j.biocon.2006.09.013.

Koel, T.M., Bigelow, P.E., Doepke, P.D., Ertel, B.D., and Mahony, D.L. 2005. Nonnative lake trout result in Yellowstone cutthroat trout decline and impacts to bears and anglers. Fisheries. 30(11):10-19. doi: 10.1577/15488446(2005)30[10:NLTRIY]2.0.CO;2.

Koel, T.M., Arnold, J.L., Bigelow, P.E., and Ruhl, M.E. 2010. Native fish conservation plan/environmental assessment. National Park Service, Yellowstone National Park, Wyoming. 
1316 Koenig, M.K., Meyer, K.A., Kozfkay, J.R., DuPont, J.M., and Schriever, E.B. 2015. Evaluating the ability of tiger muskellunge to eradicate brook trout in Idaho alpine lakes. N. Am. J. Fish. Manage. 35(4):659-670. doi:10.1080/02755947.2015.1035467.

1320 Kolar, C.S., Courtenay, W.R. Jr, and Nico, L.G. 2010. Managing undesired and invading fishes. In Inland fisheries management in North America. 3rd ed. Edited by W.A. Hubert, and M.C. Quist. American Fisheries Society, Bethesda, MD. pp. 213-259.

Kulp, M.A., and Moore, S.E. 2000. Multiple electrofishing removals for eliminating rainbow trout in a small southern Appalachian stream. N. Am. J. Fish. Manage. 20(1):259-266. doi:10.1577/1548-8675(2000)020<0259:MERFER>2.0.CO;2.

Larson, G.L., Moore, S.E., and Lee, D.C. 1986. Angling and electrofishing for removing nonnative rainbow trout from a stream in a national park. N. Am. J. Fish. Manage. 6(4):580-585. doi:10.1577/1548-8659(1986)6<580:AAEFRN>2.0.CO;2.

Lennon, R.E. 1970. Control of freshwater fish with chemicals. In Proceedings of the Fourth Vertebrate Pest Conference. Edited by R.H. Dana. West Sacramento, California. pp. 129-137.

1332 Lennox, R.J., Choi, K., Harrison, P.M., Paterson, J.E., Peat, T., Ward, T., and Cooke, S.J. 2015. Improving science-based invasive species management with physiological

1334 knowledge, concepts, and tools. Biol. Invasions. 17(8):2213-2227. doi: 10.1007/s10530-015-0884-5.

1336 Levine, J.M., and D'Antonio, C.M. 2003. Forecasting biological invasions with increasing international trade. Conserv. Biol. 17(1):322-326. doi:10.1046/j.15231739.2003.02038.x. 
Lintermans, M. 2004. Human-assisted dispersal of alien freshwater fish in Australia. New Zeal. J. Mar. Fresh. 38:481-501. doi:10.1080/00288330.2004.9517255.

Lintermans, M. 2013. A review of on-ground recovery actions for threatened freshwater fish in Australia. Mar. Freshwater Res. 64(9):775-791. doi:10.1071/MF12306.

Lintermans, M., and Bourne, C. 2011. Keeping diseases and ferals out of Cotter Reservoir. Presentation, Australian Society for Fish Biology conference, Townsville, Australia.

1346 Lintermans, M., and Raadik, T. 2003. Local eradication of trout from streams using rotenone: the Australian experience. In Proceedings of a workshop entitled "Managing invasive freshwater fish in New Zealand", Hamilton, New Zealand, 1012 May 2001. Hosted Department of Conservation, New Zealand. pp. 95-111.

1350 Lintermans, M., and Rutzou, T. 1990. Removal of feral fish from artificial ponds in the Australian National Botanic Gardens. Australian Capital Territory Parks and Conservation Service Wildlife Unit, Internal Report 90/12.

Lozano-Vilano, M.D.L., Contreras-Balderas, A.J., and Garcia-Ramirez, M.E. 2006. Eradication of spotted jewelfish, Hemichromis guttatus, from Poza San Jose del Anteojo, Cuatro Cienegas Bolson, Coahuila, Mexico. Southwestern Nat. 51(4):553555. doi:10.1894/0038-4909(2006)51[553:EOSJHG]2.0.CO;2.

Ludwig Jr, H.R., and Leitch, J.A. 1996. Interbasin transfer of aquatic biota via anglers' bait buckets. Fisheries. 21(7):14-18.

MacNamara, R., Glover, D., Garvey, J., Bouska, W., and Irons, K. 2016. Bigheaded carps (Hypophthalmichthys spp.) at the edge of their invaded range: using hydroacoustics to assess population parameters and the efficacy of harvest as a control strategy in a 
large North American river. Biol. Invasions. 18(11):3293-3307.

doi:10.1007/s10530-016-1220-4.

1364 Marking, L.L., Bills, T.D., Rach, J.J., and Grabowski, S.J. 1983. Chemical control of fish and fish eggs in The Garrison Diversion Unit, North Dakota. N. Am. J. Fish. Manage. 3(4):410-418. doi:10.1577/1548-8659(1983)3<410:CCOFAF>2.0.CO;2

Marks, J.C., Haden, G.A., O’Neill, M., and Pace, C. 2010. Effects of flow restoration and 1368 exotic species removal on recovery of native fish: lessons from a dam decommissioning. Restor. Ecol. 18(6):934-943. doi:10.1111/j.1526100X.2009.00574.x.

Meffe, G.K. 1983. Attempted chemical renovation of an Arizona spring brook for management of the endangered Sonoran topminnow. N. Am. J. Fish. Manage. 3(3):315-321. doi:10.1577/1548-8659(1983)3<315:ACROAA>2.0.CO;2.

1374 Meronek, T.G., Bouchard, P.M., Buckner, E.R., Burri, T.M., Demmerly, K.K., Hatleli, D.C., Klumb, R.A., Schmidt, S.H., and Coble, D.W. 1996. A review of fish control projects. N. Am. J. Fish. Manage. 16(1):63-74. doi:10.1577/15488675(1996)016<0063:AROFCP>2.3.CO;2.

1378 Meyer, K.A., Lamansky, J.A. Jr, and Schill, D.J. 2006. Evaluation of an unsuccessful brook trout electrofishing removal project in a small Rocky Mountain stream. N. Am. J. Fish. Manage. 26(4):849-860. doi:10.1577/M05-110.1.

Michaels, N.N. 2011. Biomanipulation of the largemouth bass Micropterus salmoides population to control invasive species and eutrophication at the Nature Conservancy's Emiquon Preserve. M.Sc. thesis, Western Illinois University, Macomb, IL. 
Molony, B., Beatty, S.J., Bird, C., and Nguyen, V. 2005. Mitigation of the negative impacts on biodiversity and fisheries values of the refurbishment of Waroona Dam, south-western Australia. Final report for the Water Corporation of Western Australia. Fisheries Research Contract Report No. 12. Department of Fisheries, Western Australia.

1390 Neilson, K., Kelleher, R., Barnes, G., Speirs, D., and Kelly, J. 2004. Use of fine-mesh monofilament gill nets for the removal of rudd (Scardinius erythrophthalmus) from a small lake complex in Waikato, New Zealand. New Zeal. J. Mar. Fresh. 38(3):525-539. doi:10.1080/00288330.2004.9517258.

1394 O’Leary, B.C., Kvist, K., Bayliss, H.R., Derroire, G., Healey, J.R., Hughes, K, Kleinschroth, F., Sciberras, M., Woodcock, P. and Pullin, A.S. 2016. The reliability of evidence review methodology in environmental science and conservation.

Environ. Sci. Policy. 64:75-82. doi:10.1016/j.envsci.2016.06.012.

1398 Pacas, C., and Taylor, M.K. 2015. Nonchemical eradication of an introduced trout from a headwater complex in Banff National Park, Canada. N. Am. J. Fish. Manage. 35(4):748-754. doi:10.1080/02755947.2015.1043412.

Padilla, D.K., and Williams, S.L. 2004. Beyond ballast water: aquarium and ornamental 1402 trades as sources of invasive species in aquatic ecosystems. Front. Ecol. Environ. 2(3):131-138. doi:10.1890/1540-9295(2004)002[0131:BBWAAO]2.0.CO;2.

1404 Parker, B.R., Schindler, D.W., Donald, D.B., and Anderson, R.S. 2001. The effects of stocking and removal of a nonnative salmonid on the plankton of an alpine lake. Ecosystems. 4(4):334-345. doi:10.1890/15409295(2004)002[0131:BBWAAO]2.0.CO;2. 
1408 Paul, A.J., Post, J.R., and Stelfox, J.D. 2003. Can anglers influence the abundance of native and nonnative salmonids in a stream from the Canadian Rocky Mountains? N. Am. J. Fish. Manage. 23(1):109-119. doi:10.1577/15488675(2003)023<0109:CAITAO $>2.0 . \mathrm{CO} ; 2$.

1412 Peterson, D.P., Rieman, B.E., Dunham, J.B., Fausch, K.D., Young, M.K. 2008. Analysis of trade-offs between threats of invasion by nonnative trout brook trout (Salvelinus fontinalis) and intentional isolation for native westslope cutthroat trout (Oncorhynchus clarkii lewisi). Can. J. Fish. Aquat. Sci. 65(4):557-573. 1416 doi:10.1139/F07-184.

Pimentel, D., Zuniga, R., and Morrison, D. 2005. Update on the environmental and 1418 economic costs associated with alien-invasive species in the United States. Ecol. Econom. 52(3):273-288. doi:10.1016/j.ecolecon.2004.10.002.

1420 Propst, D.L., Gido, K.B., Whitney, J.E., Gilbert, E.I., Pilger, T.J., Monié, A.M., Paroz, Y.M., Wick, J.M., Monzingo J.A., and Myers D.M. 2015. Efficacy of mechanically removing nonnative predators from a desert stream. River Res. Appl. 31(6):692703. doi:10.1002/rra.2768.

1424 Pullin, A.S., and Stewart, G.B. 2006. Guidelines for systematic review in conservation and environmental management. Conserv. Biol. 20(6):1647-56. doi:10.1111/j.15231739.2006.00485.x.

Ramstead, K.M., Allen, J.A., and Springer, A.E. 2012. Have wet meadow restoration 1428 projects in the Southwestern U.S. been effective in restoring geomorphology, hydrology, soils, and plant species composition? Environ. Evid. 1:11. doi:10.1186/2047-2382-1-11. 
Rayner, T.S., and Creese, R.G. 2006. A review of rotenone use for the control of nonindigenous fish in Australian fresh waters, and an attempted eradication of the noxious fish, Phalloceros caudimaculatus. New Zeal. J. Mar. Fresh. 40(3):477-486. doi:10.1080/00288330.2006.9517437.

Ricciardi, A., and MacIsaac, H.J. 2011. Impacts of biological invasions on freshwater ecosystems. In Fifty Years of Invasion Ecology: The Legacy of Charles Elton. Edited by D.M. Richardson. Blackwell Publishing Ltd, New Jersey, USA. pp. 211224.

Rinne, J.N., and Turner, P.R. 1991. Reclamation and alteration as management techniques, and a review of methodology in stream renovation. In Battle against extinction: native fish management in the American West. Edited by W.L. Minckley and J.E. Deacon. The University of Arizona Press, Tucson, AZ. pp.219244.

1444 Roberts, P.D., Stewart, G.B., and Pullin, A.S. 2006. Are review articles a reliable source of evidence to support conservation and environmental management? A

1446 comparison with medicine. Biol. Conserv. 132(4):409-423. doi:10.1016/j.biocon.2006.04.034.

1448 Rowe, D.K. 2001. Rotenone-based approaches to pest fish control in New Zealand. Managing Invasive Freshwater Fish in New Zealand.

1450 Ruiz, G.M., Carlton, J.T., Grosholz, E.D., and Hines, A.H. 1997. Global invasions of marine and estuarine habitats by non-indigenous species: mechanisms, extent, and consequences. Amer. Zool. 37(6):621-632. doi:10.1093/icb/37.6.621. 
Sala, O.E., Chapin, F.S., Armesto, J.J., Berlow, E., Bloomfield, J., and Dirzo, R., HuberSanwald, E., Huenneke, L.F., Jackson, R.B., Kinzig, A., Leemans, R., Lodge, D.M., Mooney, H.A., Oesterheld, M., Poff, N.L., Sykes, M.T., Walker, B.H., Walker, M., and Wall, D.H. 2000. Biodiversity - global biodiversity scenarios for the year 2100. Science. 287:1770-1774. doi:10.1126/science.287.5459.1770.

1458 Saunders, W.C., Budy, P., Thiede, G.P. 2015. Demographic changes following mechanical removal of exotic brown trout in an Intermountain West (USA), highelevation stream. Ecol. Freshw. Fish. 24(2):252-263. doi:10.1111/eff.12143.

Schill, D.J., Heindel, J.A., Campbell, M.R., Meyer, K.A., and Mamer, E.R.J.M. 2016. Production of a YY male brook trout broodstock for potential eradication of undesired brook trout populations. N. Am. J. Aquacult. 78(1):72-83. doi:10.1080/15222055.2015.1100149.

Schuytema, G. 1977. Biological Control of Aquatic Nuisances: a review. U.S. Environmental Protection Agency, Washington, D.C. Publ. EPA/600/3-77/084 (NTIS PB273264).

1468 Scoppettone, G.G., Rissler, P.H., Shea, S.P., and Somer, W. 2012. Effect of brook trout removal from a spawning stream on an adfluvial population of Lahontan cutthroat trout. N. Am. J. Fish. Manage. 32(3):586-596. doi:10.1080/02755947.2012.675958.

Siefkes, M.J. 2017. Use of physiological knowledge to control the invasive sea lamprey (Petromyzon marinus) in the Laurentian Great Lakes. Conserv. Physiol. 5(1):1-18. doi:10.1093/conphys/cox031. 
1474 Sih, A., Cote, J., Evans, M., Fogarty, S., and Pruitt, J. 2012. Ecological implications of behavioural syndromes. Ecol. Lett. 15(3):278-289. doi: 10.1111/j.14610248.2011.01731.x.

Simberloff, D., Martin, J., Genovesi, P., Maris, V., Wardle, D.A., Aronson, J., Courchamo, F., Galil B., Garcie-Berthou, E., Pascal M., Pysek, P., Sousa, R., Tabacchi, E. and Vila, M. 2013. Impacts of biological invasions: what's what and the way forward. Trends Ecol. Evolut. 28(1):58-66. doi:10.1016/j.tree.2012.07.013.

Smith, P.A., Leah, R.T., and Eaton, J.W. 1996. Removal of pikeperch (Stizostedion lucioperca) from a British canal as a management technique to reduce impact on prey fish populations. Ann. Zoo. Fenn. 33(3):537-545.

Sorensen, P.W. 2015. Applications of pheromones in invasive fish control and fishery conservation. In Fish pheromones and related cues. Edited by P.W. Sorensen, and B.D. Wisenden. pp.255-268. doi:10.1002/9781118794739.ch12.

Swanson, R.J. 1971. Progress report on Smelt eradication at Pasha Lake 1970. Unpublished report.

Syslo, J.M., Guy, C.S., Bigelow, P., Doepke, P.D., Ertel, B.D., and Koel, T.M. 2011. Response of non-native lake trout (Salvelinus namaycush) to 15 years of harvest in Yellowstone Lake, Yellowstone National Park. Can. J. Fish. Aquat. Sci. 68(12):2132-2145. doi:10.1139/f2011-122.

Syslo, J.M., Guy, C.S., and Cox, B.S. 2013. Comparison of harvest scenarios for the cost1494 effective suppression of lake trout in Swan Lake, Montana. N. Am. J. Fish. Manage. 33(6):1079-1090. doi:10.1080/02755947.2013.824935. 
1496 Thompson, P.D., and Rahel, F.J. 1996. Evaluation of depletion-removal electrofishing of brook trout in small Rocky Mountain streams. N. Am. J. Fish. Manage. 16(2):332339. doi:10.1577/1548-8675(1996)016<0332:EODREO>2.3.CO;2.

Thuesen, P.A., Russell, D.J., Thomson, F.E., Pearce, M.G., Vallance, T.D., and Hogan, A.E. 2011. An evaluation of electrofishing as a control measure for an invasive tilapia (Oreochromis mossambicus) population in northern Australia. Mar. Freshwater Res. 62(2):110-118. doi:10.1071/MF10057.

Trammel, M., Meismer, S., and Speas, D.W. 2004. Nonnative cyprinid removal in the 1504 lower Green and Colorado rivers, Utah. Utah Division of Wildlife Resources, Salt Lake City, UT.

1506 Vander Zanden, M.J., and Olden, J.D. 2008. A management framework for preventing the secondary spread of aquatic invasive species. Can. J. Fish. Aquat. Sci. 65(7):1512-1522. doi:10.1139/F08-099.

Varley, J.D., and Schullery P. 1995. The Yellowstone Lake crisis: confronting a lake trout invasion. National Park Service, Yellowstone Center for Resources, Yellowstone National Park, Wyoming.

1512 Vinson, M.R., Dinger, E.C., and Vinson, D.K. 2010. Piscicides and invertebrates: after 70 years, does anyone really know? Fisheries. 35(2):61-71. doi:10.1577/1548-844635.2.61.

Vitousek, P.M., Mooney, H.A., Lubchenco, J., and Melillo, J.M. 1997. Human 1516 domination of Earth’s ecosystems. Science. 277:494-499. doi:10.1126/science.277.5325.494. 
1518 Ward, A., Robinson, J., and Wilson, R.B. 2008. Management of a cutthroat trout predator to control Utah chub in a high-use sport fishery. Am. Fish. S. 62:595-608.

1520 Wydoski, R.S., and Wiley, R.W. 1999. Management of undesirable fish species. In Inland fisheries management in North America. 2nd ed. Edited by C.C. Kohler and W.A. Hubert. Am. Fish. Soc, Bethesda, Maryland. pp.403-430.

\section{Tables}

Table 1. Critical appraisal tool for study validity assessment. Reviewers provided a rating 1526 of high, medium, low, or very low for each of the specific data quality features. BA: Before-After; CI: Control-Impact; BACI: Before-After-Control-Impact.

\begin{tabular}{|c|c|c|c|c|c|}
\hline Category & $\begin{array}{l}\text { Bias and generic } \\
\text { data quality } \\
\text { features }\end{array}$ & $\begin{array}{l}\text { Specific data } \\
\text { quality } \\
\text { features }\end{array}$ & Design of assessed study & Score & Validity \\
\hline \multirow[t]{17}{*}{1} & $\begin{array}{l}\text { Selection and } \\
\text { performance bias: }\end{array}$ & $\begin{array}{l}\text { Design (i.e., } \\
\text { well-controlled) }\end{array}$ & BACI & & High \\
\hline & study design & & $\mathrm{BA}, \mathrm{CI}$, or Incomplete BACI & & Medium \\
\hline & & $\begin{array}{l}\text { Temporal } \\
\text { repetition }\end{array}$ & $\begin{array}{l}\text { Continuous Before-after (BA) time series }(>1 \\
\text { replicates before and after) }\end{array}$ & 25 & \\
\hline & & & $\begin{array}{l}\text { Interrupted BA time series ( }>1 \text { replicates before } \\
\text { and after but not consecutive) }\end{array}$ & 20 & \\
\hline & & & BA comparison ( 1 before, $>1$ after) & 15 & \\
\hline & & & BA comparison ( $>1$ before, 1 after) & 12 & \\
\hline & & & BA comparison ( 1 before, 1 after) & 10 & \\
\hline & & & Deficient BA comparison & 2 & \\
\hline & & & No BA comparison & 0 & \\
\hline & & $\begin{array}{l}\text { Spatial } \\
\text { repetition }\end{array}$ & $\begin{array}{l}\text { Site comparison/control-impact }(\mathrm{CI}) \text { (>1 replicates } \\
\text { control and impact) }\end{array}$ & 25 & \\
\hline & & & $\begin{array}{l}\text { Site comparison/control-impact (CI) (1 control, }>1 \\
\text { impact) }\end{array}$ & 15 & \\
\hline & & & $\begin{array}{l}\text { Site comparison/control-impact (CI) (>1 control, } 1 \\
\text { impact) }\end{array}$ & 12 & \\
\hline & & & $\begin{array}{l}\text { Site comparison/control-impact (CI) (1 control, } 1 \\
\text { impact) }\end{array}$ & 10 & \\
\hline & & & $\begin{array}{l}\text { Deficient CI comparison (e.g. control-data from } \\
\text { archives or not from the same period) }\end{array}$ & 2 & \\
\hline & & & No CI comparison & 0 & \\
\hline & & & Sum temporal and spatial repetition score $=$ & & \\
\hline & & & $\begin{array}{r}>15 / 50 \\
12-15 / 50\end{array}$ & & $\begin{array}{l}\text { High } \\
\text { Medium }\end{array}$ \\
\hline
\end{tabular}




\begin{tabular}{|c|c|c|c|c|}
\hline & & & $\begin{array}{r}10 / 50 \\
<10\end{array}$ & $\begin{array}{l}\text { Low } \\
\text { very low }\end{array}$ \\
\hline \multirow[t]{7}{*}{2} & \multirow[t]{7}{*}{$\begin{array}{l}\text { Assessment bias: } \\
\text { measurement of } \\
\text { outcome }\end{array}$} & \multirow[t]{4}{*}{$\begin{array}{l}\text { Measured } \\
\text { outcome }\end{array}$} & Quantitative & High \\
\hline & & & Quantitative approximations (estimates) & Medium \\
\hline & & & Semi-quantitative & Low \\
\hline & & & Qualitative & Low \\
\hline & & \multirow[t]{3}{*}{$\begin{array}{l}\text { Application } \\
\text { coverage }\end{array}$} & $\begin{array}{l}\text { Intervention was applied at an appropriate spatial } \\
\text { and temporal scale relative to target } \\
\text { species/waterbody }\end{array}$ & High \\
\hline & & & $\begin{array}{l}\text { Intervention was not applied at an appropriate } \\
\text { spatial and temporal scale relative to target } \\
\text { species/waterbody }\end{array}$ & Low \\
\hline & & & Lacking sufficient information to judge & Low \\
\hline \multirow[t]{10}{*}{3} & \multirow{10}{*}{$\begin{array}{l}\text { Selection and } \\
\text { Performance bias: } \\
\text { baseline comparison }\end{array}$} & \multirow[t]{5}{*}{ Habitat type } & $\begin{array}{l}\text { Intervention and comparator sites homogenous i.e. } \\
\text { similar at baseline }\end{array}$ & High \\
\hline & & & $\begin{array}{l}\text { Intervention and comparator sites moderately } \\
\text { comparable with respect to habitat characteristics }\end{array}$ & Medium \\
\hline & & & $\begin{array}{l}\text { Intervention and comparator sites hardly } \\
\text { comparable due to different habitat }\end{array}$ & Low \\
\hline & & & Lacking sufficient information to judge & Low \\
\hline & & & $\begin{array}{l}\text { N/A if BA design and before measurement taken } \\
\text { immediately prior to eradication treatment }\end{array}$ & \\
\hline & & \multirow[t]{5}{*}{$\begin{array}{l}\text { Other } \\
\text { confounding } \\
\text { environmental } \\
\text { factors }\end{array}$} & Intervention and comparator sites homogenous & High \\
\hline & & & $\begin{array}{l}\text { Intervention and comparator sites moderately } \\
\text { comparable with respect to confounding factors }\end{array}$ & Medium \\
\hline & & & $\begin{array}{l}\text { Intervention and comparator sites hardly } \\
\text { comparable with respect to confounding factors }\end{array}$ & Low \\
\hline & & & Lacking sufficient information to judge & Low \\
\hline & & & $\begin{array}{l}\text { N/A if BA design and before measurement taken } \\
\text { immediately prior to eradication treatment }\end{array}$ & \\
\hline
\end{tabular}

1528 Note: Deficient BA comparison: (1) before-data is not from the same site(s); (2) >5 years between before or after replicates; or (3) when there is only 1 before or after replicate and 1530 that replicate is $>5$ years either prior to or following intervention.

1532

1534 
Table 2. Criteria for rating intervention(s) effectiveness aimed at eradication and/or

1544 population control of non-native fish and respective rating.

\begin{tabular}{|c|c|c|}
\hline \multicolumn{2}{|c|}{ Criteria for rating intervention(s) effectiveness when the goal was: } & \multirow{2}{*}{$\begin{array}{c}\text { Effectiveness } \\
\text { rating }\end{array}$} \\
\hline Eradication & Population control & \\
\hline $\begin{array}{l}\text { Evidence exists to conclude that the } \\
\text { intervention(s) was successful in } \\
\text { eradicating or likely eradicating a } \\
\text { non-native fish by comparison of } \\
\text { quantitative data from the } \\
\text { comparator group and the } \\
\text { intervention group, or stated by } \\
\text { author that a successful eradication } \\
\text { or likely eradication had occurred. }\end{array}$ & $\begin{array}{l}\text { Evidence exists to conclude that } \\
\text { the intervention(s) was } \\
\text { successful in reducing non- } \\
\text { native fish population size (e.g., } \\
\text { abundance, density, biomass) by } \\
\text { comparison of quantitative data } \\
\text { from the comparator group and } \\
\text { the intervention group, or stated } \\
\text { by author that a successful } \\
\text { reduction of non-native fish } \\
\text { population size had occurred. }\end{array}$ & Effective \\
\hline $\begin{array}{l}\text { Evidence exists to conclude that the } \\
\text { intervention(s) was successful in } \\
\text { eradicating or likely eradicating a } \\
\text { non-native fish by comparison of } \\
\text { quantitative data, or stated by } \\
\text { authors that a successful eradication } \\
\text { or likely eradication had occurred } \\
\text { but: (1) only in some, and not all } \\
\text { treated waterbodies; (2) a non- } \\
\text { native was known (or thought) to } \\
\text { be re-introduced illegally after } \\
\text { treatment, or (3) the project was } \\
\text { still on-going. }\end{array}$ & $\begin{array}{l}\text { Evidence exists to conclude that } \\
\text { the intervention(s) was } \\
\text { successful in reducing non- } \\
\text { native fish population size (e.g., } \\
\text { abundance, density, biomass) by } \\
\text { comparison of quantitative data } \\
\text { from the comparator group and } \\
\text { the intervention group, or stated } \\
\text { by author that a successful } \\
\text { reduction of non-native fish } \\
\text { population size had occurred } \\
\text { but: (1) the project was still on- } \\
\text { going; (2) only for a particular } \\
\text { size class, suggesting subsequent } \\
\text { removal treatments were needed } \\
\text { to sustain low population size; } \\
\text { (3) only in some, and not all } \\
\text { treated waterbodies, or (4) the }\end{array}$ & $\begin{array}{l}\text { Partly } \\
\text { effective }\end{array}$ \\
\hline
\end{tabular}


Evidence exists to conclude that the intervention(s) was not successful in eradicating a non-native fish by comparison of quantitative data from the comparator group and the intervention group, or stated by author that eradication had not occurred. reduction in abundance was only initial, being followed by compensatory reproduction of mature fish that survived removal efforts or immigration and recruitment pulses soon after treatment.

Evidence exists to conclude that Ineffective the intervention(s) was not successful in reducing nonnative fish population size (e.g., abundance, density, biomass) by comparison of quantitative data from the comparator group and the intervention group, or stated by author that a successful reduction of non-native fish population size had not occurred (i.e., there was either no change in population size or an increase in non-native fish population size with an applied intervention). 
1560 Table 3. Study validity of the included removal projects. BA: Before-After; CI: ControlImpact; BACI: Before-After-Control-Impact.

\begin{tabular}{|c|c|}
\hline & $\begin{array}{l}\text { no. of } \\
\text { projects }\end{array}$ \\
\hline \multicolumn{2}{|l|}{ Very low } \\
\hline Temporal repetition: Deficient BA comparison & 22 \\
\hline \multicolumn{2}{|l|}{ Low or unclear } \\
\hline Study design: Sum temporal and spatial repetition score $(=10 / 50)$ & 28 \\
\hline Measurement of outcome: Semi-quantitative or qualitative & 52 \\
\hline $\begin{array}{l}\text { Application coverage: Intervention was not applied at an appropriate } \\
\text { spatial and temporal scale relative to target species/waterbody }\end{array}$ & 3 \\
\hline Application coverage: Lacking sufficient information to judge & 33 \\
\hline $\begin{array}{l}\text { Baseline comparison: Intervention and comparator sites hardly } \\
\text { comparable with respect to confounding factors }\end{array}$ & 1 \\
\hline Baseline comparison: Lacking information to judge for either & 5 \\
\hline \multicolumn{2}{|l|}{ Medium } \\
\hline $\begin{array}{l}\text { Study design: Well-controlled design (e.g., BA, CI, or Incomplete } \\
\text { BACI design) }\end{array}$ & 21 \\
\hline Study design: Sum temporal and spatial repetition score $(=12-15 / 50)$ & 12 \\
\hline Measurement of outcome: Quantitative approximations & 11 \\
\hline $\begin{array}{l}\text { Baseline comparison: Intervention and comparator sites moderately } \\
\text { comparable with respect to habitat }\end{array}$ & 2 \\
\hline $\begin{array}{l}\text { Baseline comparison: Intervention and comparator sites hardly } \\
\text { comparable with respect to confounding factors }\end{array}$ & 1 \\
\hline
\end{tabular}


Table 4. Number of cases of each intervention type within each intervention category in

1578 relation to the stated goal(s) of the study. Note, a data set could have $>1$ cases if $>1$ intervention types were applied, either from the same or different intervention category.

1580 Eradication/Population control: the stated goal was either eradication or population size control.

\begin{tabular}{|c|c|c|c|c|}
\hline & Eradication & $\begin{array}{l}\text { Population } \\
\text { control }\end{array}$ & $\begin{array}{c}\text { Eradication/ } \\
\text { Population control }\end{array}$ & Total \\
\hline \multicolumn{5}{|l|}{ Physical } \\
\hline Passive netting & 22 & 20 & 9 & 51 \\
\hline Active netting & 3 & 8 & 1 & 12 \\
\hline Angling & 1 & 3 & & 4 \\
\hline Electrofishing & 20 & 47 & 9 & 76 \\
\hline Unknown & 1 & & & 1 \\
\hline \multicolumn{5}{|l|}{ Harvest } \\
\hline Passive/Active netting & & 6 & & 6 \\
\hline Angling & 2 & 3 & 1 & 6 \\
\hline \multicolumn{5}{|l|}{ Chemical } \\
\hline Rotenone & 37 & 2 & 1 & 40 \\
\hline Antimycin & 11 & & & 11 \\
\hline Other & 6 & 2 & & 8 \\
\hline Unknown & 1 & & & 1 \\
\hline \multicolumn{5}{|l|}{ Biological } \\
\hline Predator control & 2 & 2 & 1 & 5 \\
\hline \multicolumn{5}{|l|}{ Environmental } \\
\hline Dewatering & 5 & 1 & 1 & 7 \\
\hline \multicolumn{5}{|l|}{ Other } \\
\hline Explosives & & & 1 & 1 \\
\hline
\end{tabular}




\section{Figure captions}

Fig. 1. Results of literature search and study selection process showing the final number

1594 of studies included in the review synthesis. See Table S2 for details on exclusion categories.

1596 Fig. 2. Year of publication of the 95 primary study sources.

Fig. 3. Percentage of the total number of removal projects within a given time period in

1598 relation to study validity. Number of removal projects per time period in brackets.

Fig. 4. Number of included data sets per country in relation to the stated goal(s) of the

1600 project. Eradication/control: the stated goal was either eradication or population size control.

1602 Fig. 5. Percentage of data sets in relation to the number of main interventions applied for removal of non-native fish.

1604 Fig. 6. The number of included data sets per intervention category used alone (i.e., no other main interventions were used) to either eradicate or control population size of a 1606 non-native fish species in relation to the effectiveness rating and study validity. 


\section{Appendix}

1608 Table A1. List of included primary study sources along with article ID. No. of data sets per study: an article could have (1) data for more than one non-native fish species; (2)

1610 evaluated different removal measure in different waterbodies. 


\section{Supplementary material}

1612

er-2018-0049.R1suppla

1614 Text S1. Variances between search outlined in the review protocol and the systematic review.

1616 Text S2. Description of database and search engine literature searches.

Text S3. List of specialist organization websites searched.

1618 Text S4. Additional methods.

$1620 \quad$ er-2018-0049.R1supplb

1622 Table S1. List of relevant reviews hand searched to identify relevant articles that were not found using the search strategy.

1624

Table S2. List of articles excluded on the basis of full-text assessment and reasons for

1626 exclusion.

1628 Table S3. List of primary study sources for the included removal studies on the basis of full-text assessments, along with supplementary articles, that were selected for critical 1630 appraisal/data extraction. 
1632 er-2018-0049.R1supplc

Table S4. Study validity assessments.

1634

\section{er-2018-0049.R1suppld}

1636 Table S5. Data extraction sheet.

\section{8 er-2018-0049.R1supple}

Table S6. Number of data sets for each targeted non-native fish species for the North

1640 American countries in relation to the stated goal of the project.

1642 Table S7. Number of data sets for each targeted non-native fish species in Europe, Africa, Australia and New Zealand in relation to the stated goal of the project.

Table S8. Summary characteristics and results of studies implementing antimycin alone 1646 for eradication of a non-native fish species.

1648 Table S9. Summary characteristics and results of studies implementing rotenone alone for eradication of a non-native fish species.

1650

Table S10. Summary characteristics and results of studies implementing electrofishing 1652 alone for eradication of a non-native fish species. 
1654 Table S11. Summary characteristics and results of studies implementing passive netting/trapping alone for eradication of a non-native fish species.

1656

Table S12. Summary characteristics and results of studies implementing electrofishing 1658 alone for population control of a non-native fish species.

1660 Table S13. Summary characteristics and results of studies implementing passive or active netting alone for population control of a non-native fish species.

1662

Table S14. Summary characteristics and results of studies implementing combinations of 1664 physical removal measures for eradication of a non-native fish species.

1666 Table S15. Summary characteristics and results of studies implementing combinations of physical removal measures for population size control of a non-native fish species.

Table S16. Summary characteristics and results of studies implementing various

1670 combinations of removal measures for population control (POPLN) or eradication (ERAD) of a non-native fish species.

1672

\section{er-2018-0049.R1supplf}

Fig. S1. The availability of pre-, during- and post-removal outcome data from the 1676 included studies from Oceania, Africa, and Europe. 
1678 Fig. S2. The availability of pre-, during- and post-removal outcome data from the included North American studies.

1680

Fig. S3. The availability of pre-, during- and post-eradication/control outcome data from 1682 included projects for more American studies (continued from Fig. S2). 


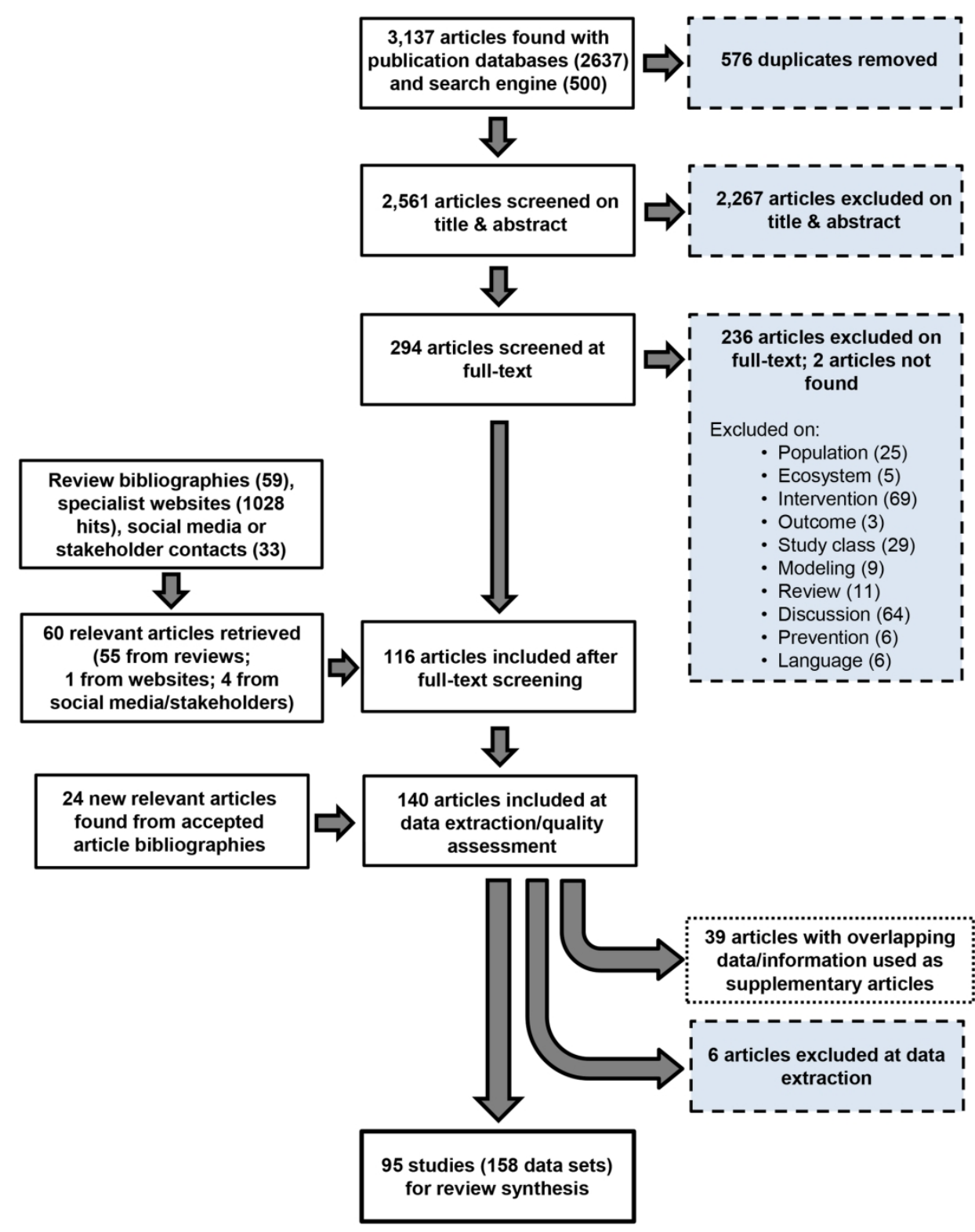

Fig. 1. Results of literature search and study selection process showing the final number of studies included in the review synthesis. See Table S2 for details on exclusion categories.

$177 \times 221 \mathrm{~mm}(300 \times 300 \mathrm{DPI})$ 


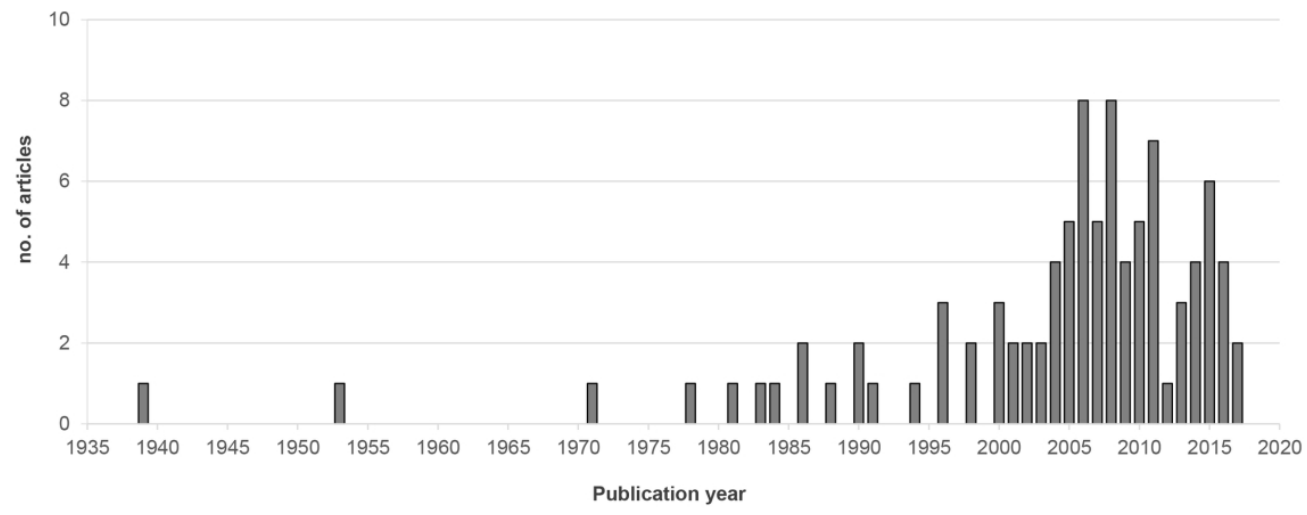

Fig. 2. Year of publication of the 95 primary study sources.

$182 \times 73 \mathrm{~mm}(300 \times 300 \mathrm{DPI})$ 


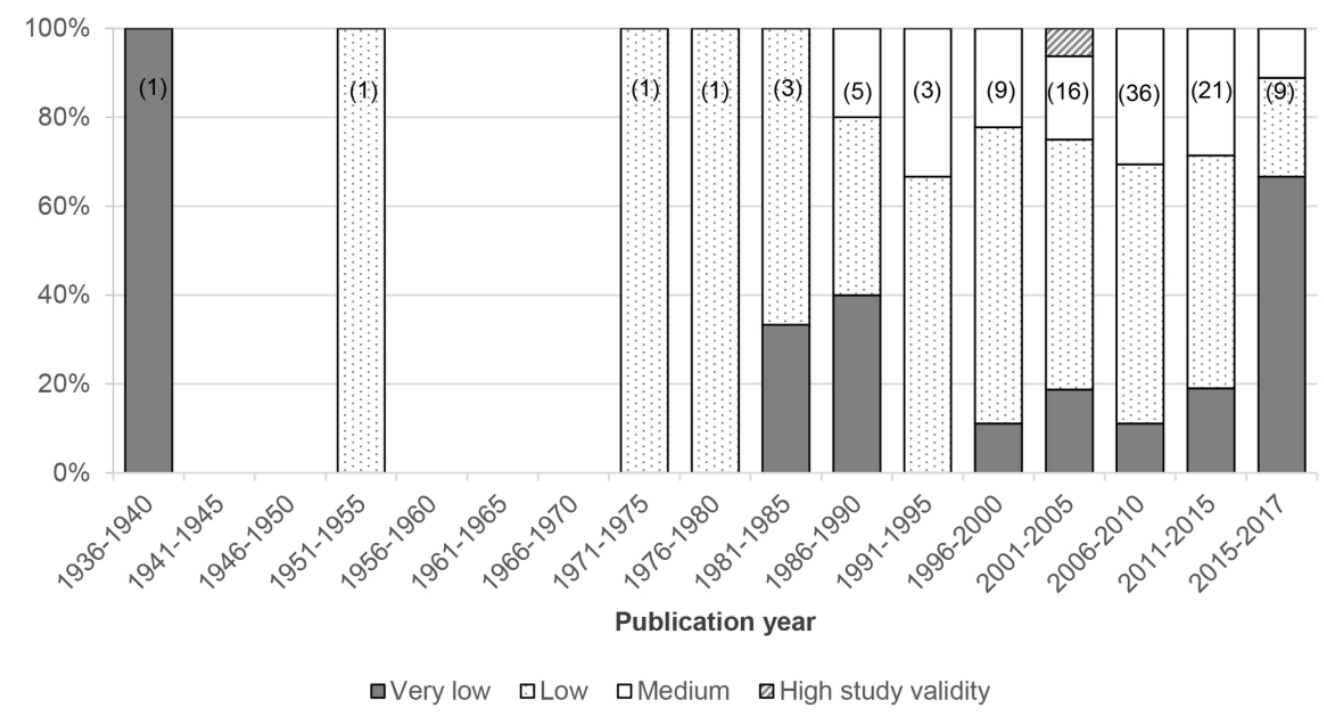

Fig. 3. Percentage of the total number of removal projects within a given time period in relation to study validity. Number of removal projects per time period in brackets.

$86 \times 47 \mathrm{~mm}(600 \times 600 \mathrm{DPI})$ 


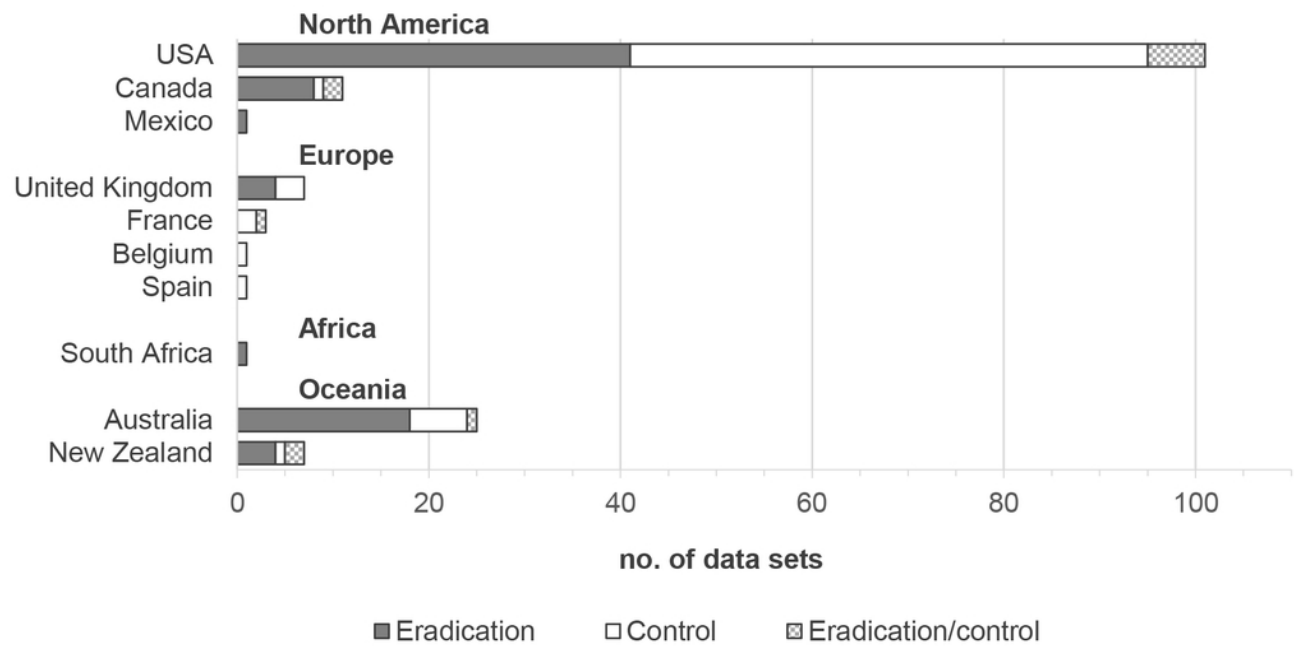

Fig. 4. Number of included data sets per country in relation to the stated goal(s) of the project. Eradication/control: the stated goal was either eradication or population size control.

$86 \times 43 \mathrm{~mm}(300 \times 300$ DPI $)$ 


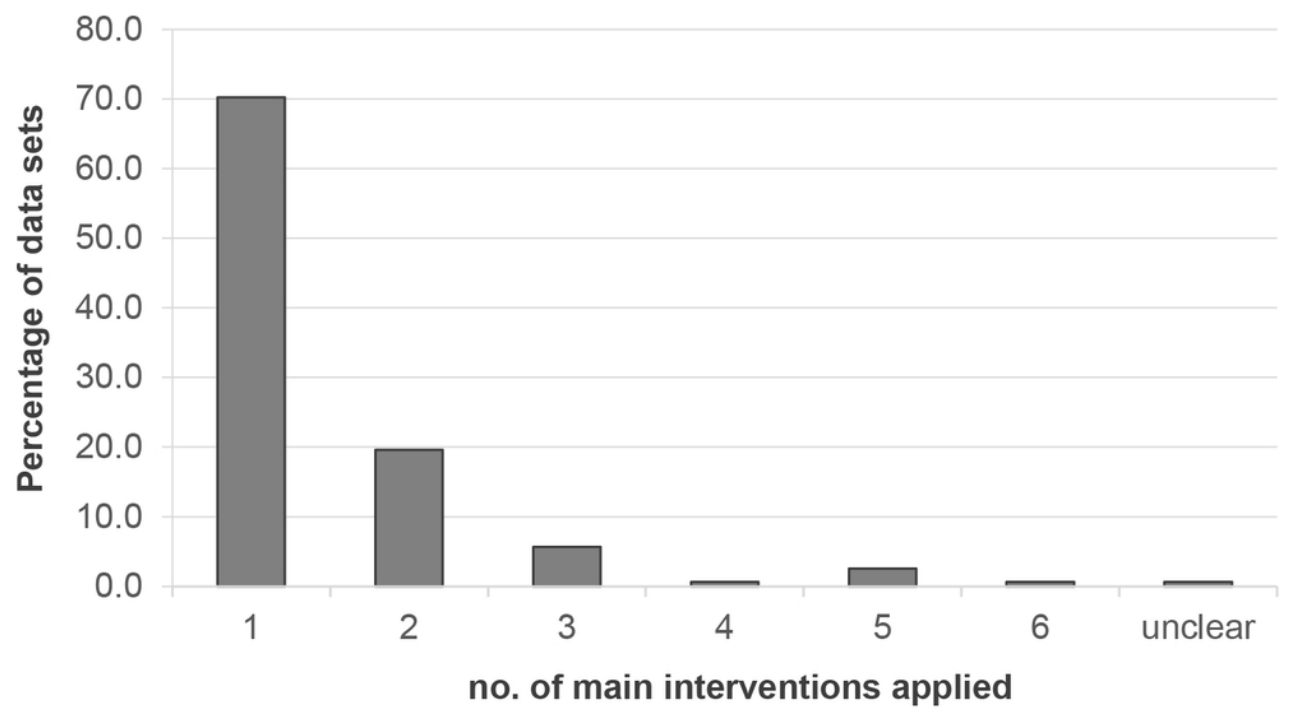

Fig. 5. Percentage of data sets in relation to the number of main interventions applied for removal of nonnative fish.

$86 \times 47 \mathrm{~mm}(300 \times 300 \mathrm{DPI})$ 


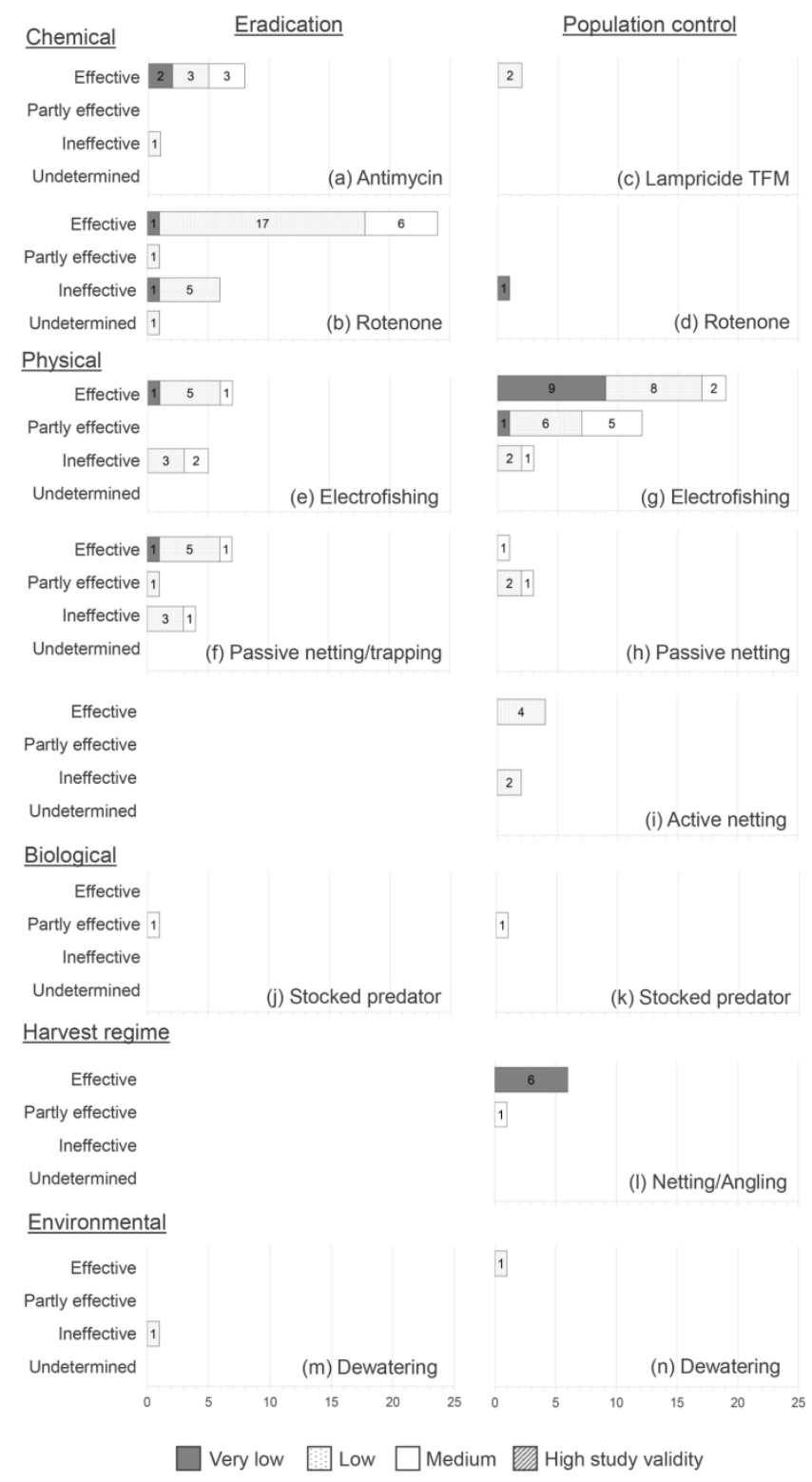

Fig. 6. The number of included data sets per intervention category used alone (i.e., no other main interventions were used) to either eradicate or control population size of a non-native fish species in relation to the effectiveness rating and study validity.

$126 \times 236 \mathrm{~mm}(300 \times 300 \mathrm{DPI})$ 


\section{Appendix}

2 Table A1. List of included primary study sources along with article ID. No. of data sets

per study: an article could have (1) data for more than one non-native fish species; (2)

4 evaluated different removal measure in different waterbodies.

ID Primary study source citation $\begin{gathered}\text { No. of data } \\ \text { sets per } \\ \text { study }\end{gathered}$

1 Lintermans, M., and Rutzou, T. 1990. Removal of feral fish from artificial ponds in the Australian National Botanic Gardens. Australian Capital Territory Parks and Conservation Service Wildlife Unit, Internal Report 90/12.

2 Lintermans, M., and Bourne, C. 2011. Keeping diseases and ferals out of Cotter Reservoir. Presentation to the Australian Society for Fish Biology annual conference, July 2011.

3 Lintermans, M. 2000. Recolonization by the mountain galaxias Galaxias olidus of a montane stream after the eradication of rainbow trout Oncorhynchus mykiss. Mar. Freshwater. Res. 51(8):799-804.

4 Lintermans, M., and Raadik, T. 2003. Local eradication of trout from streams using rotenone: the Australian experience. In Proceedings of a workshop entitled "Managing invasive freshwater fish in New Zealand", Hamilton, New Zealand, 10-12 May 2001. Hosted Department of Conservation, New Zealand. pp. 95-111.

5 Pinto, L., Chandrasena, N., Pera, J., Hawkins, P., Eccles, D., and Sim, R. 2005. Managing invasive carp (Cyprinus carpio L.) for habitat enhancement at Botany Wetlands, Australia. Aquat. Conserv. 15(5):447462.

6 O'Meara, J., and Darcovich, K. 2008. Gambusia control through the manipulation of water levels in Narawang Wetland, Sydney Olympic Park 2003-2005. Aust. Zool. 34(3):285-290.

7 Rayner, T.S., and Creese, R.G. 2006. A review of rotenone use for the control of non-indigenous fish in Australian fresh waters, and an attempted eradication of the noxious fish, Phalloceros caudimaculatus. New. Zeal. J. Mar. Fresh. 40(3):477-486.

8 Burchmore, J., Faragher, R., and Thorncraft, G. 1990. Occurrence of the introduced oriental weatherloach (Misgurnus anguillicaudatus) in the Wingecarribee River, New South Wales. In Introduced and translocated fishes and their ecological effect. Edited by D.A. Pollard. Australian Government Publishing Service, Canberra. pp 38-46.

9 Pearce, M.G., Perna, C., and Hedge, S. 2009. Survey of Eureka Creek and Walsh River fish community following the removal of tilapia using rotenone. Queensland Primary Industries and Fisheries, Brisbane.

10 Thuesen, P.A., Russell, D.J., Thomson, F.E., Pearce, M.G., Vallance, T.D., and Hogan, A.E. 2011. An evaluation of electrofishing as a control measure for an invasive tilapia (Oreochromis mossambicus) population in northern Australia. Mar. Freshwater. Res. 62(2):110-118. 
11 Arthington, A.H., McKay, R.J., Russell, D.J., and Milton, D.A. 1984.

Occurrence of the introduced cichlid Oreochromis mossambicus (Peters) in Queensland. Mar. Freshwater. Res. 35(2):267-272.

12 Hall, D.A. 1988. The eradication of European carp and goldfish from the Leigh Creek Retention Dam. Safish 12:15-16.

13 Jarvis, D. 1998. New life for Brushy Lagoon. On the Rise: Inland Fisheries Commission Newsletter. 27(1):4-5.

14 Diggle, J., Day, J., and Bax, N. 2004. Eradicating European carp from Tasmania and implications for national European carp eradication. Moonah Tasmania, Australia: Inland Fisheries Service. 2000/182.

15 Donkers, P., Patil, J.G., Wisniewski, C., and Diggle, J.E. 2012. Validation of mark-recapture population estimates for invasive common carp, Cyprinus carpio, in Lake Crescent, Tasmania. J. Appl. Ichthyol. 28(1):7-14.

16 Inland Fisheries Service. 2005. Inland Fisheries Service Annual Report 2004-05. Inland Fisheries Service, Moonah, Tasmania.

17 Morgan, D.L., and Beatty, S.J. 2006b. Re-establishment of native freshwater fishes in Bull Creek. Report prepared for Melville City Council. Centre for Fish and Fisheries Research, Murdoch University, Murdoch, Western Australia.

18 Molony, B., Beatty, S.J., Bird, C., and Nguyen V. 2005. Mitigation of the negative impacts on biodiversity and fisheries values of the refurbishment of Waroona Dam, south-western Australia. Final report for the Water Corporation of Western Australia. Fisheries Research Contract Report No. 12. Department of Fisheries, Western Australia.

19 Beatty, S.J., and Morgan, D.L. 2017. Rapid proliferation of an endemic galaxiid following eradication of an alien piscivore (Perca fluviatilis) from a reservoir. J. Fish. Biol. 90(3):1090-1097.

20 Morgan, D.A., and Beatty, S.J. 2006a. Overview of the feral goldfish control programme in the Vasse River, Western Australia: 2004-2006. Report to the GeoCatch. Centre for Fish and Fisheries Research, Murdoch University, Murdoch, Western Australia.

21 Louette, G., and Declerck, S. 2006. Assessment and control of non-indigenous brown bullhead Ameiurus nebulosus populations using fyke nets in shallow ponds. J. Fish. Biol. 68(2):522-531.

22 Parker, B.R., Schindler, D.W., Donald, D.B., and Anderson, R.S. 2001. The effects of stocking and removal of a nonnative salmonid on the plankton of an alpine lake. Ecosystems. 4(4):334-345.

23 Earle, J.E., and Lajeunesse, B.L. 2007. Evaluation of a brook trout removal project to establish westslope cutthroat trout in Canmore Creek, Alberta. In Proceedings of Wild Trout IX symposium: Sustaining wild trout in a changing world, West Yellowstone, MT, 9-12 October 2007. Edited by Bob Carline and Carol LoSapio. pp. 9-12.

24 Pacas, C., and Taylor, M.K. 2015. Nonchemical eradication of an introduced trout from a headwater complex in Banff National Park, Canada. N. Am. J. Fish. Manag. 35(4):748-754.

25 Earle, J.E., Paul, A.J., and Stelfox, J.D. 2010. Quirk Creek population estimates and one-pass electrofishing removal of brook trout-2009. Fish and Wildlife Division, Alberta Sustainable Resource Development, Cochrane, Alberta. Unpublished report.

26 Davis, C. 2011. Haha Lake Northern Pike Control. Ministry of Forests, Lands, and Natural Resource Operations. 
27 Connell, C.B., B.L. Dubee, and P.J. Cronin. 2002. Using rotenone to eradicate chain pickerel, Esox niger, from Despres Lake, New Brunswick, Canada. NB DNRE Fisheries Management Report. 2002-01-E.

28 Hooper, W.C., and Gilbert, J.C. 1978. Goldfish eradication, standing crop estimates of fishes and fisheries management recommendations for a small, mesotrophic New Brunswick lake. Fisheries Management Report No. 6. Fish and Wildlife Branch, Department of Natural Resources, Fredericton, NB, Canada.

29 [DFO] Department of Fisheries and Oceans Canada. 2013. Review of control and eradication activities in 2010 to 2012 targeting Smallmouth Bass in Miramichi Lake, New Brunswick. DFO Can. Sci. Advis. Sec. Sci. Resp. 2013/012.

30 Swanson, R.J. 1971. Progress report on Smelt eradication at Pasha Lake 1970. Unpublished report.

31 Dimond, P.E. Mandrak, N.E., and Brownson, B. 2010. Summary of the rapid response to round goby (Neogobius melanostomus) in Pefferlaw Brook with an evaluation of the national rapid response framework based on the Pefferlaw Brook experience. DFO Can. Sci. Advis. Sec. Res. Doc. 2010/036.

32 Britton, J.R., Davies, G.D., and Brazier, M. 2009. Eradication of the invasive Pseudorasbora parva results in increased growth and production of native fishes. Ecol. Freshwat. Fish. 18(1):8-14.

33 Britton, J.R., Davies, G.D., and Brazier, M. 2010. Towards the successful control of the invasive Pseudorasbora parva in the UK. Biol. Inv. 12(1):125131.

34 Britton, J.R., Brazier, M., Davies, G.D., and Chare, S.I. 2008. Case studies on eradicating the Asiatic cyprinid Pseudorasbora parva from fishing lakes in England to prevent their riverine dispersal. Aquat. Conserv. 18(6):867876.

35 Ibbotson, A., and Klee, C. 2002. Impacts and subsequent control of an introduced predator: the case of pike, Esox lucius, in Chew Valley Lake. In Management and Ecology of Lake and Reservoir Fisheries. Edited by I.G. Cowx. Blackwell Science, Oxford. pp. 203-216.

36 Evangelista, C., Britton, R.J., and Cucherousset, J. 2015. Impacts of invasive fish removal through angling on population characteristics and juvenile growth rate. Ecol. Evol. 5(11):2193-2202.

37 Caudron, A., and Champigneulle, A. 2011. Multiple electrofishing as a mitigate tool for removing nonnative Atlantic brown trout (Salmo trutta L.) threatening a native Mediterranean brown trout population. Eur. J. Wildlife. Res. 57(3):575-583.

38 Cucherousset, J., Paillisson, J.M., and Carpentier, A. 2006. Is mass removal an efficient measure to regulate the North American catfish Ameiurus melas outside of its native range? J. Freshwat. Ecol. 21(4):699704.

39 Lozano-Vilano, M.D.L., Contreras-Balderas, A.J., and Garcia-Ramirez, M.E. 2006. Eradication of spotted jewelfish, Hemichromis guttatus, from Poza San Jose del Anteojo, Cuatro Cienegas Bolson, Coahuila, Mexico. Southwest. Nat. 51(4):553-555. 
40 Rowe, D.K., and Champion, P.D. 1994. Biomanipulation of plants and fish

to restore Lake Parkinson: a case study and its implications. In Restoration of aquatic habitats. New Zealand Limnological Society 1993 Annual Conference, Wellington, New Zealand, 10-12 May 1993. Edited by K.J. Collier. Department of Conservation, New Zealand. pp. 53-65.

41 David, B. 2003. Eradication of koi carp from an enclosed pond in Houhora. Department of Conservation Internal Working Report. Department of Conservation, Hamilton (unpublished).

42 Closs, G.P., Ludgate, B., and Goldsmith, R.J. 2001. Controlling European perch (Perca fluviatilis): lessons from an experimental removal. In Proceedings of a workshop entitled "Managing invasive freshwater fish in New Zealand", Hamilton, New Zealand, 10-12 May 2001. Hosted Department of Conservation, New Zealand. pp. 37-48.

43 Neilson, K., Kelleher, R., Barnes, G., Speirs, D., and Kelly, J. 2004. Use of fine-mesh monofilament gill nets for the removal of rudd (Scardinius erythrophthalmus) from a small lake complex in Waikato, New Zealand. New. Zeal. J. Mar. Fresh. 38(3):525-539.

44 Hicks, B.J., Hamilton, D.P., Ling, N., and Wood, S.A. 2007. Top down or bottom up? Feasibility of water clarity restoration in the lower Karori Reservoir by fish removal. CBER Contract Report 70. Karori Wildlife Sanctuary Trust.

45 Weyl, O.L.F., Barrow, S., Bellingan, T., Dalu, T., Ellender, B.R., Esler, K., Impson, D., Gouws, J., Jordaan, M., Villet, M., Wassermann, R.J., and Woodford, DJ. 2016. Monitoring of invertebrate and fish recovery following river rehabilitation using rotenone in the Rondegat River. Report to the Water Research Commission. No. 2261/1/16.

46 Ruiz-Navarro, A., Verdiell-Cubedo, D., Torralva, M., and Oliva-Paterna, F.J. 2013. Removal control of the highly invasive fish Gambusia holbrooki and effects on its population biology: learning by doing. Wildl. Res. 40(1):82-89.

47 Smith, P.A., Leah, R.T., and Eaton, J.W. 1996. Removal of pikeperch (Stizostedion lucioperca) from a British Canal as a management technique to reduce impact on prey fish populations. Ann. Zool. Fennici. 33:537-545.

48 Meffe, G.K. 1983. Attempted chemical renovation of an Arizona springbrook for management of the endangered Sonoran topminnow. N. Am. J. Fish. Manag. 3(3):315-321.

49 Coggins, L.G. Jr. 2008. Active adaptive management for native fish conservation in the Grand Canyon: implementation and evaluation. Doctoral dissertation, University of Florida, Gainesville, FL.

50 Marks, J.C., Haden, G.A., O'Neill, M., and Pace, C. 2010. Effects of flow restoration and exotic species removal on recovery of native fish: lessons from a dam decommissioning. Restoration. Ecol. 18(6):934-943.

51 Hill, J., and Cichra, C. 2005. Eradication of a reproducing population of convict cichlids, Cichlasoma nigrofasciatum (Cichlidae) in north-central Florida. Florida Scientist. 68(2):65-74.

52 Koenig, M.K., Meyer, K.A., Kozfkay, J.R., DuPont, J.M., and Schriever, E.B. 2015. Evaluating the ability of Tiger Muskellunge to eradicate Brook Trout in Idaho Alpine Lakes. N. Am. J. Fish. Manag. 35(4):659-670. 
53 Aiken, M.A. 2014. The efficacy of small-scale removal of an invasive species (redbreast sunfish, Lepomis auritus) by electrofishing. M.Sc. thesis, Faculty of the Graduate School, Western Carolina University, Cullowhee, NC.

54 Buktenica, M.W., Hering, D.K., Girdner, S.F., Mahoney, B.D., and Rosenlund, B.D. 2013. Eradication of nonnative Brook Trout with electrofishing and antimycin-A and the response of a remnant Bull Trout population. N. Am. J. Fish. Manag. 33(1):117-129.

55 Beamesderfer, R.C. 2000. Managing fish predators and competitors: deciding when intervention is effective and appropriate. Fisheries. 25(6):18-23.

56 Trammel, M., Meismer, S., and Speas, D.W. 2004. Nonnative cyprinid removal in the lower Green and Colorado rivers, Utah. Utah Division of Wildlife Resources. Salt Lake City, UT. Publication \#05-10.

57 Hoffman, R.L., Larson, G.L., and Samora, B. 2004. Responses of Ambystoma gracile to the removal of introduced nonnative fish from a mountain lake. J. Herpetol. 38(4):578-585.

58 Thompson, P.D., and Rahel, F.J. 1996. Evaluation of depletion-removal electrofishing of brook trout in small Rocky Mountain streams. N. Am. J. Fish. Manag. 16(2):332-339.

59 Moore, S.E., Larson, G.L., and Ridley, B. 1986. Population control of exotic rainbow trout in streams of a natural area park. Environ. Manage. 10(2):215-219.

60 Shepard, B.B., Nelson, L.M., Taper, M.L., and Zale, A.V. 2014. Factors influencing successful eradication of nonnative brook trout from four small Rocky Mountain streams using electrofishing. N. Am. J. Fish. Manag. 34(5):988-997.

61 Gresswell, R.E. 1991. Use of antimycin for removal of brook trout from a tributary of Yellowstone Lake. N. Am. J. Fish. Manag. 11(1):83-90.

62 Firehammer, J.A., Vitale, A.J., and Hallock, S.A. 2009. Implementation of fisheries enhancement opportunities on the Coeur d'Alene Reservation. Coeur d'Alene Tribe Fish, Water, and Wildlife Program, Portland OR. 2007 Annual Report \#P113336.

63 Carmona-Catot, G., Moyle, P.B., Aparicio, E., Crain, P.K., Thompson, L.C., and García-Berthou, E. 2010. Brook trout removal as a conservation tool to restore Eagle Lake rainbow trout. N. Am. J. Fish. Manag. 30(5):1315-1323.

64 National Park Service (NPS). 2015. Bright Angel Creek Trout Reduction Project. Grand Canyon National Park's Fisheries program. Available from www.nps.gov/grca/learn/nature/trout-reduction.htm [accessed 1 March 2017].

65 Burdick, B.D. 2008. Removal of smallmouth bass and four other centrarchid fishes from the Upper Colorado and Lower Gunnison Rivers: 2004-2006. U.S. FWS Final Report prepared for the Upper Colorado River Endangered Fish Recovery Program. Recovery Program Project. 126.

66 Dunker, K.J., Sepulveda, A.J., Massengill, R.L., Olsen, J.B., Russ, O.L., Wenburg, J.K., and Antonovich, A. 2016. Potential of Environmental DNA to Evaluate Northern Pike (Esox lucius) Eradication Efforts: An Experimental Test and Case Study. PloS one, 11(9):e0162277.

67 Finlayson B.J., Eilers, J.M., Huchko, H.A. 2014. Fate and Behaviour of rotenone in Diamond Lake, Oregon, USA following invasive tui chub eradication. Environ. Toxicol. Chem. 33(7):1650-1655 
68 Barrows, M. B. 1939. Elimination of yellow perch from a lake by use of derris root. J. Wildl. Manage. 3(2):131-133.

69 MacNamara, R., Glover, D., Garvey, J., Bouska, W., and Irons, K. 2016. Bigheaded carps (Hypophthalmichthys spp.) at the edge of their invaded range: using hydroacoustics to assess population parameters and the efficacy of harvest as a control strategy in a large North American river. Biol. Invasions. 18(11):3293-3307.

70 Scoppettone, G.G., Rissler, P.H., Shea, S.P., and Somer, W. 2012. Effect of Brook Trout removal from a spawning stream on an adfluvial population of Lahontan Cutthroat Trout. N. Am. J. Fish. Manag. 32(3):586-596.

71 Lee, D.P. 2001. Northern pike control at Lake Davis, California. In Rotenone in fisheries: Are the rewards worth the risks? Edited by Richard L. Cailteux, Leo DeMong, Brian J. Finlayson, William Horton, William McClay, Rosalie A. Schnick, and Charlie Thompson. Am. Fish. Soc. Symp. pp. 55-61.

72 Cahoon, W.G. 1953. Commercial carp removal at Lake Mattamuskeet, North Carolina. J. Wildl. Manage. 17(3):312-317.

73 Bajer, P.G., Chizinski, C.J., and Sorensen, P.W. 2011. Using the Judas technique to locate and remove wintertime aggregations of invasive common carp. Fish. Manag. Ecol. 18(6):497-505.

74 Weidel, B.C., Josephson, D.C., and Kraft, C.E. 2007. Littoral fish community response to smallmouth bass removal from an Adirondack lake. Trans. Am. Fish. Soc. 136(3):778-789.

75 Saunders, W.C., Budy, P., and Thiede, G.P. 2015. Demographic changes following mechanical removal of exotic brown trout in an Intermountain West (USA), high-elevation stream. Ecol. Freshwat. Fish. 24(2):252-263.

76 Larson, G.L., Moore, S.E., and Lee, D.C. 1986. Angling and electrofishing for removing nonnative rainbow trout from a stream in a national park. N. Am. J. Fish. Manag. 6(4):580-585.

77 Kulp, M.A., and Moore, S.E. 2000. Multiple electrofishing removals for eliminating rainbow trout in a small southern Appalachian stream. N. Am. J. Fish. Manag. 20(1):259-266.

78 Knapp, R.A., Boiano, D.M., and Vredenburg, V.T. 2007. Removal of nonnative fish results in population expansion of a declining amphibian (mountain yellow-legged frog, Rana muscosa). Biol. Cons. 135(1):11-20.

79 Knapp, R.A., and Matthews, K.R. 1998. Eradication of nonnative fish by gill netting from a small mountain lake in California. Restoration. Ecol. 6(2):207-213.

80 Rinne, J.N., Minckley, W.L., and Hanson, J.N. 1981. Chemical treatment of Ord Creek, Apache County, Arizona, to re-establish Arizona trout. Journal of the Arizona-Nevada Academy of Science. 16(3):74-78.

81 Meyer, K.A., Lamansky Jr, J.A., and Schill, D.J. 2006. Evaluation of an unsuccessful brook trout electrofishing removal project in a small Rocky Mountain stream. N. Am. J. Fish. Manag. 26(4):849-860.

82 Moore, S.E., Kulp, M.A., Hammonds, J., and Rosenlund, B. 2005. Restoration of Sams Creek and an assessment of Brook Trout restoration methods, Great Smoky Mountains National Park. Water Resources Division, National Park Service, Department of the Interior. NPS/NRWRD/NRTR-2005/342. 
83 Franssen, N.R., Davis, J.E., Ryden, D.W., and Gido, K.B. 2014. Fish community responses to mechanical removal of nonnative fishes in a large southwestern river. Fisheries. 39(8):352-363.

84 Boogaard, M.A., Bills, T.D., Selgeby, J.H., and Johnson, D.A. 1996. Evaluation of piscicides for control of ruffe. N. Am. J. Fish. Manag. 16(3):600-607.

85 Walston, L.J., and Mullin, S.J. 2007. Responses of a pond-breeding amphibian community to the experimental removal of predatory fish. Am. Midl. Nat. 157(1):63-73.

86 Baker, G., Darby, N., and Williams, T. 2008. Bonneville Cutthroat Trout Restoration Project: Great Basin National Park. Department of the Interior, National Park Service. Natural Resources Program Center. NPS/NRPC/NRR - 2008/055.

87 Ward, A., Robinson, J., and Wilson, R.B. 2008. Management of a Cutthroat Trout predator to control Utah Chub in a high-use sport fishery. Am. Fish. Soc. Symp. 62:595-608.

88 Michaels, N.N. 2011. Biomanipulation of the largemouth bass Micropterus salmoides population to control invasive species and eutrophication at the Nature Conservancy's Emiquon Preserve. M.Sc. Thesis, Western Illinois University, Macomb, IL.

89 Lazur, A., Early, S., and Jacobs, J.M. 2006. Acute Toxicity of 5\% Rotenone to Northern Snakeheads, N. Am. J. Fish. Manag. 26(3):628-630.

90 Propst, D.L., Gido, K.B., Whitney, J.E., Gilbert, E.I., Pilger, T.J., Monié, A.M., Paroz, Y.M., Wick, J.M., Monzingo, J.A., and Myers, D.M. 2015. Efficacy of mechanically removing nonnative predators from a desert stream. River. Res. Appl. 31(6):692-703.

91 Jolley, J.C., Willis, D.W., DeBates, T.J., and Graham, D.D. 2008. The effects of mechanically reducing northern pike density on the sport fish community of West Long Lake, Nebraska, USA. Fish. Manag.

Ecol. 15(4):251-258.

92 Finney, S.T., and Haines, G.B. 2008. Northern pike removal, smallmouth bass monitoring, and native fish monitoring in the Yampa River, Hayden to Craig Reach, 2004-2006. U.S. Fish and Wildlife Service, Colorado River Fish Project. Synthesis Report. Project No. 98b.

93 Hawkins, J., Walford, C., and Hill, A. 2009. Smallmouth bass control in the middle Yampa River, 2003-2007. Final Report to the Upper Colorado River Endangered Fish Recovery Program, Project No. 125.

94 Ertel, B.D., Heim, K.C., Arnold, J.L., Detjens, C.R., and Koel, T.M. 2017. Preservation of Native Cutthroat Trout in Northern Yellowstone. Yellowstone. Science. 25(1):35-41.

95 Bigelow, P.E., Doepke, P.D., Bertel, B.D., Guy, C.S., Syslo, J.M., and Koel, T.M. 2017. Yellowstone Science. 25(1):53-59. 
Table A2. Recommendations for future study components to improve evaluations of non-native fish removal methods.

\begin{tabular}{|c|c|c|c|}
\hline Project element & Description & Impact on assessment & Recommendations \\
\hline Before data & $\begin{array}{l}\text { often before data are not } \\
\text { reported or a single before } \\
\text { period }>5 \text { years prior to } \\
\text { intervention is reported }\end{array}$ & $\begin{array}{l}\text { limits correct interpretation of } \\
\text { intervention effectiveness }\end{array}$ & $\begin{array}{l}\text { 1. report all years for which before data were actually } \\
\text { collected (including presence immediately prior to } \\
\text { treatment); } \\
\text { 2. collect continuous years of before data (when } \\
\text { appropriate) or try avoid gaps in time longer than } 5 \\
\text { years prior to intervention; } \\
\text { 3. seek out existing monitoring data to supplement } \\
\text { current projects }\end{array}$ \\
\hline After data & $\begin{array}{l}\text { often } \leq 1 \text { year of post- } \\
\text { treatment monitoring being } \\
\text { conducted }\end{array}$ & $\begin{array}{l}\text { limits correct interpretation of } \\
\text { intervention effectiveness and } \\
\text { recovery of the ecosystem }\end{array}$ & $\begin{array}{l}\text { 1. collect multiple years of after data; } \\
\text { 2. strive for continuous years of data collection; } \\
\text { 3. seek out collaborations with scientists from other } \\
\text { agencies, or local universities for opportunities to } \\
\text { extend post-treatment monitoring when resources } \\
\text { are limited }\end{array}$ \\
\hline $\begin{array}{l}\text { Outcome } \\
\text { measure }\end{array}$ & $\begin{array}{l}\text { often a qualitative outcome } \\
\text { measure was used for } \\
\text { comparator and/or } \\
\text { intervention group (e.g., the } \\
\text { presence of a non-native } \\
\text { before intervention and the } \\
\text { numbers removed after) }\end{array}$ & $\begin{array}{l}\text { precludes quantitative assessment of } \\
\text { intervention effectiveness (i.e., } \\
\text { standard effect size calculations) }\end{array}$ & $\begin{array}{l}\text { 1. use quantitative outcome measures for both } \\
\text { assessment periods (e.g., relative } \\
\text { abundance/density both before and after) }\end{array}$ \\
\hline $\begin{array}{l}\text { Management } \\
\text { objective }\end{array}$ & $\begin{array}{l}\text { lack of explicit management } \\
\text { objective(s) for the study }\end{array}$ & $\begin{array}{l}\text { outcomes cannot be adequately } \\
\text { compared against objectives for } \\
\text { correct interpretation of intervention } \\
\text { effectiveness }\end{array}$ & $\begin{array}{l}\text { 1. develop a clear statement of management } \\
\text { objective(s) at the beginning of the project; } \\
2 \text {. develop study designs with those specific target } \\
\text { objective(s) in mind (e.g., use appropriate temporal } \\
\text { scale for monitoring assessment periods) }\end{array}$ \\
\hline Control site(s) & $\begin{array}{l}\text { lack of control sites being } \\
\text { incorporated into study } \\
\text { designs }\end{array}$ & $\begin{array}{l}\text { without comparison of control sites } \\
\text { with treatment sites, there is no way } \\
\text { to know whether apparent effects of } \\
\text { removal interventions are in fact } \\
\text { due to the intervention and not a } \\
\text { confounding variable }\end{array}$ & $\begin{array}{l}\text { 1. locate and include suitable analogous control sites } \\
\text { in close proximity within a study area }\end{array}$ \\
\hline
\end{tabular}


